\title{
Evaluation of Hydraulic Controls for Leakage Intervention in Carbon Storage Reservoirs
}

\author{
Christopher Zahasky* and Sally M. Benson \\ Stanford University, Department of Energy Resources Engineering, School of Earth Sciences, Stanford, USA \\ *Corresponding author E-mail address: zahasky@stanford.edu
}

\begin{abstract}
Assuring the storage security of geologically sequestered $\mathrm{CO}_{2}$ is essential for proper project management and long-term emissions reductions. Storage security relies not only on comprehensive site characterization prior to injection and careful reservoir management, but also on having a suite of intervention and remediation strategies available to implement if leakage occurs. In this study sequential stages of intervention are analyzed and evaluated. The first step in halting leakage is likely to be stopping $\mathrm{CO}_{2}$ injection in the vicinity of the leak (also termed passive remediation). Results indicate that while passive remediation can reduce the leakage rate by an order of magnitude, completely stopping leakage may often require implementation of additional measures. Additional measures evaluated here focus largely on hydraulic controls, whereby water is injected or produced in or above the $\mathrm{CO}_{2}$ injection reservoir in order to terminate leakage. The degree of residual trapping determines the extent to which leakage is ultimately reduced. For example, water injection into the overlying aquifer directly above a fault was able to completely terminate leakage for as long as water injection continues. Remediation was even more effective when water injection above the fault was combined with reservoir fluid production. We also show that in addition to hydraulic control methods, extracting $15-25 \%$ of the injected $\mathrm{CO}_{2}$ can lead to permanent leakage termination. The role of reservoir heterogeneity on remediation efficacy was also examined and found to reduce the total amount of $\mathrm{CO}_{2}$ leaked compared to a homogeneous reservoir. Overall this study demonstrates that temporally limited, multi-stage intervention strategies such as hydraulic barriers can permanently stop $\mathrm{CO}_{2}$ leakage from storage reservoirs into overlying aquifers.
\end{abstract}

\section{Keywords}

$\mathrm{CO}_{2}$ sequestration; leakage; remediation; hydraulic barriers; heterogeneity; TOUGH2

\section{Introduction}

Carbon capture and sequestration (CCS) can aid in the reduction of global carbon emissions as energy systems around the world transition away from carbon intensive fuel sources. Despite the promise of CCS, it has been confined to a small fraction of large $\mathrm{CO}_{2}$ emissions point sources around the world. While socioeconomic hurdles (e.g. global climate policy uncertainty, uncertain technology risks, public acceptance, and added costs of electricity generation with $\mathrm{CO}_{2}$ capture) provide the largest barrier to widespread implementation of CCS, some questions remain about short and long-term storage security. 
Several mechanisms have the potential to compromise the security of supercritical $\mathrm{CO}_{2}$ stored in deep saline aquifers or depleted oil and gas reservoirs (Benson and Cook 2005; Friedmann and Nummendal 2003; Celia et al. 2005; Nordbotten, Celia and Bachu 2004, Dockrill and Shipton 2010). The two most likely pathways for leakage are through abandoned wells and fault or fracture zones. Due to the large uncertainty associated with characterizing the subsurface, these features could go undetected and thus provide potential fluid migration pathways from the storage reservoir to overlying aquifers or even to the earth's surface. To prepare for such an event, contingency plans are needed before implementing a large scale injection project.

When supercritical $\mathrm{CO}_{2}$ is injected into deep saline formations there are usually two major driving mechanisms which try to force $\mathrm{CO}_{2}$ from the reservoir into which it is injected. The first mechanism is the buoyancy force created by the density instability of a less dense $\mathrm{CO}_{2}$ plume injected into a formation containing denser water and brine. The second mechanism is the pressure buildup in the reservoir resulting from the injection of $\mathrm{CO}_{2}$. Carbon dioxide injection will typically increase the pore pressure in the storage reservoir relative to the pore pressure in overlying aquifer. Absent a high quality seal, this pressure gradient will drive fluid from the injection reservoir to the overlying aquifer.

Carbon dioxide is retained in the storage reservoir by four trapping mechanisms (Benson et al. 2005; Gunter et al. 2004). These mechanisms are structural, residual, dissolution, and mineral trapping. Structural trapping is provided by shale and other geologic materials that have very low permeability and very high capillary entry pressure. This trapping mechanism is key for preventing the buoyant rise of $\mathrm{CO}_{2}$ from the storage reservoir. Residual trapping (also referred to as phase trapping) occurs as water imbibes into pore space occupied by $\mathrm{CO}_{2}$, resulting in trapped ganglia of $\mathrm{CO}_{2}$. The extent of this trapping mechanism is dependent on the initial $\mathrm{CO}_{2}$ saturation and on the reservoir rock properties (Krevor et al. 2012; Krevor et al., 2015). Dissolution (also known as solubility trapping) occurs when $\mathrm{CO}_{2}$ dissolves in the resident reservoir brine, resulting in a fluid that is denser than the surrounding fluid. The solubility of $\mathrm{CO}_{2}$ in water is around $5 \%$ at typical reservoir conditions-though this can vary significantly depending on groundwater salinity and chemistry (Gunter et al. 2004). Over geologic time this mechanism is thought to be able to permanently trap over $90 \%$ of injected $\mathrm{CO}_{2}$ (McPherson and Cole 2000). Finally, mineral trapping arises when dissolved $\mathrm{CO}_{2}$ acts as a weak acid and reacts with minerals in the surrounding rock to form bicarbonate ions or carbonate ions (Gunter et al. 2004). These ions may then result in the formation of carbonate minerals thereby permanently trapping the injected $\mathrm{CO}_{2}$ The contribution of these trapping mechanisms is dependent not only on the physical and chemical characteristics of the storage system but also on the interplay between the trapping mechanisms. Doughty and Myer (2009) highlighted that structural trapping can hinder residual or dissolution trapping whereas if the plume is allowed to migrate further vertically and/or horizontally, this spreading will promote residual and dissolution trapping.

A number of different remediation methods have been proposed to stop $\mathrm{CO}_{2}$ leakage, many of which are currently used in ground water remediation and/or the oil and gas industry (Manceau et al. 2014). Proposed strategies generally belong to one of the following categories: (1) hydraulic controls and pressure management (Buscheck et al. 2012; Le Guenan and Rohmer 2011; Reveillere et al. 2012; Zahasky and Benson 2014a), (2) production and removal of injected $\mathrm{CO}_{2}$ (Esposito and Benson 2012), (3) biologically active barriers (Cunningham et al. 2009), and (4) sealants and other physical barriers (Ito et al. 2014). Hydraulic controls rely on altering the pore pressure in the overlying aquifer and storage reservoir by injecting water or producing reservoir fluid. By altering the pore pressure it is possible to counteract the mechanisms working to drive the $\mathrm{CO}_{2}$ from the reservoir, resulting in leakage termination and in some cases leakage reversal (i.e. pushing $\mathrm{CO}_{2}$ back into the storage reservoir). For clarity throughout this study, fluid in the reservoir and overlying aquifer fluid is termed "brine", and injected fluids are referred to as water.

In this study, simulation models are employed to evaluate the feasibility of slowing or stopping leakage of $\mathrm{CO}_{2}$ through faults in the reservoir caprock by stopping injection and implementing hydraulic controls. We focus specifically on small, subseismic faults, which may be difficult to detect prior to injection (Gauthier and Lake 1993; Pickering and Peacock 1997). In this model, $\mathrm{CO}_{2}$ is injected into a reservoir capped by an impermeable seal; above the seal is an aquifer. At some injection sites, this overlying aquifer may exist above the target caprock, at other sites it be considered an upper portion of the containment zone that is overlain by another and potentially more substantial seal. When the $\mathrm{CO}_{2}$ is 
injected, the plume migrates along the bottom of the caprock and eventually reaches a permeable fault zone providing a pathway for $\mathrm{CO}_{2}$ to leak from the storage reservoir into the overlying aquifer. To terminate leakage, a number of intervention methods are evaluated including $\mathrm{CO}_{2}$ injection shut off, hydraulic controls such as water injection in the overlying aquifer above the fault and reservoir fluid production away from the $\mathrm{CO}_{2}$ plume, and $\mathrm{CO}_{2}$ extraction from the storage reservoir. To understand the influence that fault permeability has on the efficacy of different intervention methods both $10 \mathrm{mD}$ and $100 \mathrm{mD}$ fault scenarios are evaluated. Lower permeability faults have been analyzed previously and found to have negligible leakage rates and consequently were not considered here (Zahasky and Benson 2014b). Similarly, higher permeability faults have also been studied, but leakage rates were not expected to be significantly higher than the cases studied here because the fault is no longer the leakage rate-limiting factor (Zahasky and Benson 2014b).

Reservoir heterogeneity has the potential to create flow barriers, compartmentalization, and preferential flow pathways for injected $\mathrm{CO}_{2}$ and thus may enhance or inhibit both leakage from the reservoir and the effectiveness of various remediation strategies. In order to test the influence of reservoir geology on the leakage rates of $\mathrm{CO}_{2}$ and the ability of hydraulic controls to slow or stop leakage, a number of heterogeneous reservoir models are developed. Results from the homogeneous models are compared to results from heterogeneous models on the century timescale in order to understand the long-term leakage behavior resulting from various hydraulic barrier intervention strategies. In this section the influence of leakage detection is also evaluated by examining two different leakage scenarios. In the first scenario early leakage detection occurs; in the second scenario the leak is not detected until a significant amount of $\mathrm{CO}_{2}$ has escaped from the storage reservoir. The analysis highlights the importance of monitoring and verification and how leakage detection influences the ability for hydraulic controls to terminate potential leakage.

It is important to emphasize that this is not meant to be an exhaustive study analyzing or optimizing the remediation of many different leakage scenarios and geologic environments, but is meant to demonstrate the feasibility of using hydraulic controls to slow or eliminate leakage relative to other remediation options. Detailed leakage response at specific storage sites will require analysis and simulation studies based on the site characterization and system conditions.

\section{Methods and model development}

\subsection{Fault characterization}

Geological faults and fractures are observed at spatial scales ranging from tectonic to thin sections. Here we focus on subseismic fault zones or fault zones that are below the resolution of most surface seismic surveys, which could easily go undetected during site characterization. While the subseismic threshold can vary based on fault properties and observation techniques, it is generally considered to include fault zones with displacements or offsets of less than 10 to 15 meters (Gauthier and Lake 1993; Kim and Sanderson 2005; Pickering and Peacock 1997). Based on this initial constraint of fault displacement, published correlations between fault displace and length (Cowie and Scholz 1992; Elliot 1976; Krantz 1988; Walsh and Watterson 1988; Peacock and Sanderson 1991; Peacock 1991; Muraoka and Kamata 1983; Opheim and Gudmundsson 1989; Kim and Sanderson 2005), and fault displacement and fault width (Sperrevik et al. 2002; Hull 1988; Evans 1990; Knott et al. 1996), can be used to establish an appropriate fault zone geometry. Results of this characterization lead to a fault model with negligible slip (i.e. no offset of the reservoir units), $500 \mathrm{~m}$ in length, $100 \mathrm{~m}$ in vertical extent, and three meters wide (Zahasky 2014).

Great uncertainty exists in constraining the permeability of fractures and fault zones. Much of this uncertainty is due to the fact that the permeability of fractures and fault zones is dependent on host rock composition, stress history, slip distribution, confining pressure, interaction between fault segments, deformation mechanism, and burial history/lithification (Fisher and Knipe 2001). For this study two fault permeabilities are evaluated, $10 \mathrm{mD}$ and $100 \mathrm{mD}$. These values are chosen because one value is lower than the reservoir permeability, as permeability in fault zones can drop due to cataclasis, 
reduction in grain size, and cementation (Antonellini and Aydin 1994; Fossen et al. 2007; Fisher and Knipe 2001; Matthai et al. 1998). The $100 \mathrm{mD}$ fault zone has a higher average permeability than the reservoir as can happen during grain disaggregation or if brittle gouge is present in the fault (Fisher and Knipe 2001; Fossen et al. 2007). As mentioned above, we consider these to be reasonable bounding cases to assess the efficacy of hydraulic controls. They are not intended to represent best estimates of fault zone permeability at any specific geologic location.

\subsection{Simulation model development}

Simulations are carried out using TOUGH2, a fully implicit numerical simulator designed for modeling nonisothermal, multiphase flow in porous and fractured media (Pruess et al. 1999). The simulation model has dimensions of $5 \mathrm{~km}$ by $5 \mathrm{~km}$ by $100 \mathrm{~m}$ thick. The horizontal boundary grid cells have volume multiplication factors of 1050 such that the model is effectively of infinite areal extent. The vertical boundaries are closed. These domain conditions were chosen such that the model is large enough to prevent $\mathrm{CO}_{2}$ from reaching the boundary of the model. The relatively close proximity of the constant pressure boundaries to the fault zone make the pressure changes required for effective hydraulic controls more difficult to attain and consequently provide conservative estimates of the injection rates required to stop leakage. Using the constraints on subseismic fault geometry and permeability described in the previous section, areal fault zone dimensions of three meters by 500 meters are assigned in the model. For simplicity, the permeability structure that typically exists in fault zones in sedimentary rocks (e.g. Caine et al. 1996) is ignored and a single permeability value is assigned to the fault zone which cuts vertically through the entire thickness of the model. The distance of the fault from the injection well is $500 \mathrm{~m}$. The grid is structured and locally refined around the injection well and fault zone. The smallest grid cells have a width of one meter and the largest grid cells near the boundary are $500 \mathrm{~m}$ wide. The stratigraphy of the model is characterized by a lower reservoir with a thickness of $68 \mathrm{~m}$, a caprock which is $12 \mathrm{~m}$ thick, and an overlying aquifer with a thickness of 20 meters. For simplicity the modeled fault has no vertical displacement. The lower reservoir and overlying aquifer have mean permeabilities of 28 $\mathrm{mD}$ and the caprock has a permeability of 0.2 nanodarcy. Relative permeability and capillary pressure curves for the reservoir and aquifer are based on the Arqov sandstone as described in Pini et al (2012). The initial pressure and temperature conditions are established based on typical values for a reservoir located at a depth $1600 \mathrm{~m}$ below the water table. Initially, $\mathrm{CO}_{2}$ is injected at a constant rate of $7.9 \mathrm{~kg} / \mathrm{s}$ $(0.25 \mathrm{Mt} / \mathrm{yr})$ into the lower reservoir over a completion interval of $0 \mathrm{~m}$ to $55 \mathrm{~m}$ from the bottom of the reservoir. This rate was selected to enable long-term injection into a relatively low permeability reservoir while injecting at a high enough rate such that the total emissions of $1 \mathrm{Mt} /$ year could be stored with three or four wells of this size. Sensitivity of $\mathrm{CO}_{2}$ leakage as a function of different model parameters was performed in Zahasky and Benson (2013b). A complete table of simulation model parameters is given in the Appendix (Table A1). 


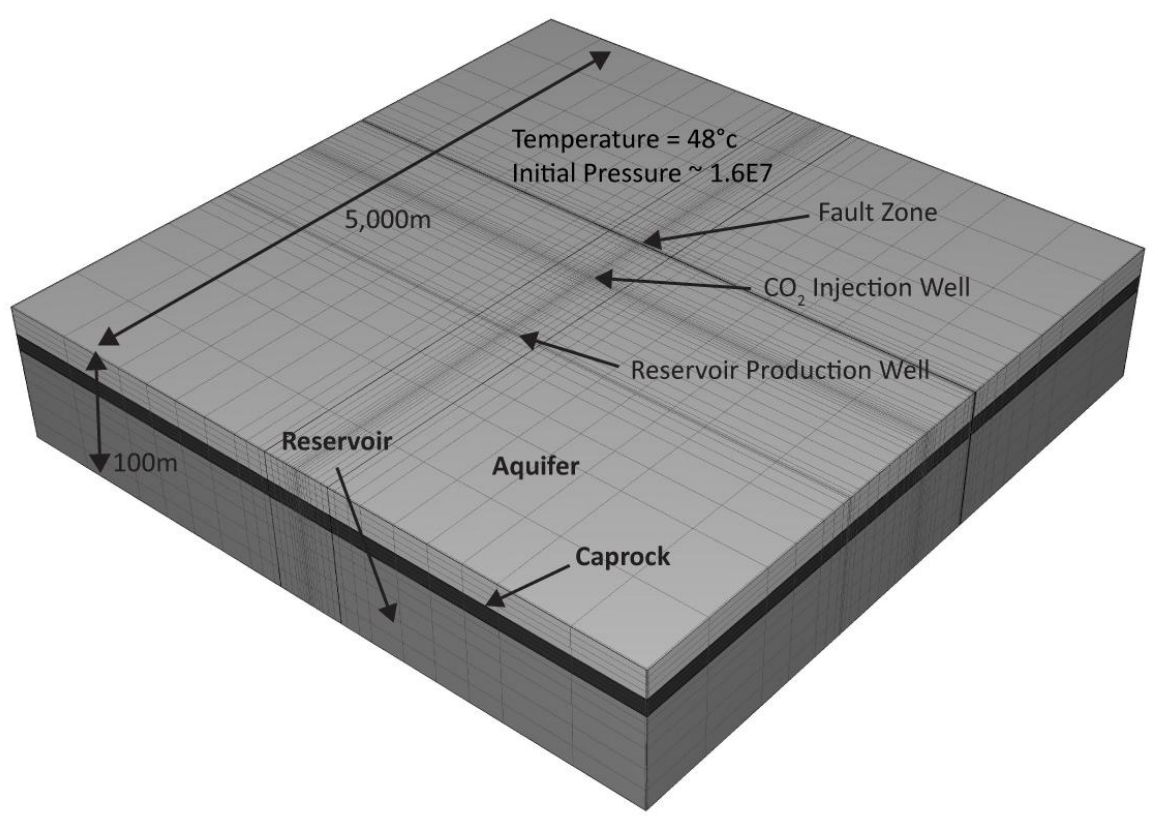

Fig 1. Grid geometry model used for TOUGH2 simulations. Note the height of the system is scaled 10x greater than the $x$ and $y$ directions (from Zahasky and Benson 2014a).

\subsection{Residual trapping}

A parameter that deserves detailed attention due to its importance in controlling plume stabilization and remediation effectiveness is $\mathrm{CO}_{2}$ residual trapping. In order to incorporate residual trapping into the simulation model, a history-dependent trapping model implemented in the TOUGH2-ECO2N module by Patterson and Falta (2012) was employed. This model utilizes the commonly used Land residual trapping method (Land 1968), shown in Equation 1 and Equation 2.

$$
\begin{aligned}
& S_{\text {trapped }}=\frac{S_{i}}{1+\left(C \cdot S_{i}\right)} \\
& C=\frac{1}{S_{\text {nmax }}}-1
\end{aligned}
$$

In these equations $C$ refers to the Land trapping coefficient. The residual trapping coefficient $\left(S_{n \max }\right)$ describes the maximum possible non-wetting residual saturation (i.e. the residual $\mathrm{CO}_{2}$ saturation if the $\mathrm{CO}_{2}$ saturation is equal to one prior to imbibition). The initial $\mathrm{CO}_{2}$ in the pore spaces is given by $S_{i}$, and the amount of $\mathrm{CO}_{2}$ that is residually trapped is $S_{\text {trapped. }}$. An evaluation of different residual trapping coefficients in Figure 2 shows how the selection of $S_{n \max }$ impacts the residually trapped $\mathrm{CO}_{2}$ saturations. When $S_{n \text { max }}$ is larger, more of the $\mathrm{CO}_{2}$ is trapped in the pore space during imbibition.

Trapping coefficient and residual trapping measurements have been measured extensively in the lab (Bennion and Bachu 2005; Bennion and Bachu 2008; Bachu 2013; Shi et al. 2011; Pentland et al. 2011; Krevor et al. 2012; Akbarabadi and Piri 2013; Ruprecht et al. 2014; Burnside and Naylor 2014; Krevor et al., 2015), but also in field experiments (Laforce et al. 2014). Capillary trapping has been carried out on a number of reservoir rock samples. Krevor et al. (2012) measured Land trapping coefficients in cores from four different sandstone formations and found that core-averaged $S_{\text {nmax }}$ values ranged from 0.21 to 0.33 and is heavily dependent on pore scale heterogeneity. Other laboratory experimental studies (Bachu 2013; Akbarabadi and Piri 2013; Pentland et al. 2011; Ruprecht et al. 2014) using a variety of methods for measuring initial and residual saturation values yielded similar, and sometimes higher, residual trapping results. Residual trapping values were also measured during one phase of the CO2CRC Otway demonstration project (Paterson et al, 2013). During this project, supercritical $\mathrm{CO}_{2}$ was injected 
into a deep saline aquifer and monitored until plume immobilization occurred. Measurements from this experiment found residual $\mathrm{CO}_{2}$ saturation values in the reservoir between 11-20\% (Laforce et al. 2014), again suggesting a $S_{n \max }$ trapping coefficient of around 0.3. Based on these studies, a Land trapping $S_{n \max }$ value equal to 0.3 is assigned in the remediation model scenarios in the following sections.

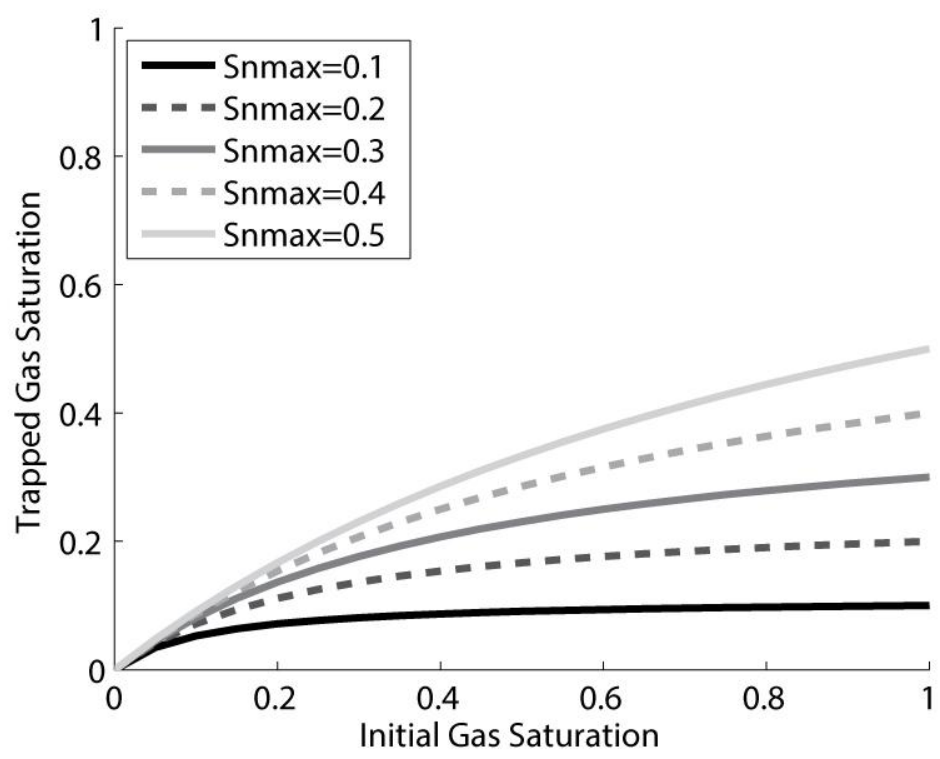

Fig 2. Land trapping characteristic curves for different $S_{n \max }$ coefficients. Note that the residual gas saturation is only equal to the $S_{n \max }$ coefficient if the initial gas saturation is $100 \%$.

\subsection{Heterogeneous model development}

For this study, 16 heterogeneous reservoir models are developed which represent a variety of different geologic scenarios. The nature of the heterogeneity is modeled after typical depositional environments found in sedimentary basins. These facies are channel systems, layered systems, large dunes, and small dunes (Figure 3). The heterogeneity is discretized into up to six lithofacies, from shale with a permeability of $10 \mu \mathrm{D}$, to coarse sand with a permeability of $1 \mathrm{D}$ (see Table A2 for details of each lithofacies). The capillary pressure curves are scaled with permeability for each lithotype. The volume weighted median permeability of the reservoir models are fixed at $28 \mathrm{mD}$, the same permeability as the homogeneous model. The average volume weighted geometric mean for the models is roughly $23 \mathrm{mD}$. The heterogeneity is only applied to the injection reservoir; the overlying aquifer remained homogeneous with a permeability of $28 \mathrm{mD}$. Since reservoir heterogeneity is the focus of this section, the fault permeability is fixed at $10 \mathrm{mD}$. Permeability is isotropic within grid cells. The system gridding and discretization is identical to that of the homogeneous model.

The heterogeneous models were constructed with two different techniques. The channel and large dune systems are regridded models originally constructed using the Stanford Geostatistical Modeling Software (Remy et al. 2009). The layer and small dune models are constructed in Matlab. In the layered models, additional $28 \mathrm{mD}$ cells are added to the layers in order to guarantee some vertical connectivity between layers. Different layered models had different permeability sequences to represent reservoirs that fine upwards, coarsen upwards, or have discontinuities that prevent vertical permeability trends. Due to the coarseness of the gridding near the model boundaries, much of the character of the facies systems is lost away from injection wells and fault zone (Figure 3 ). 


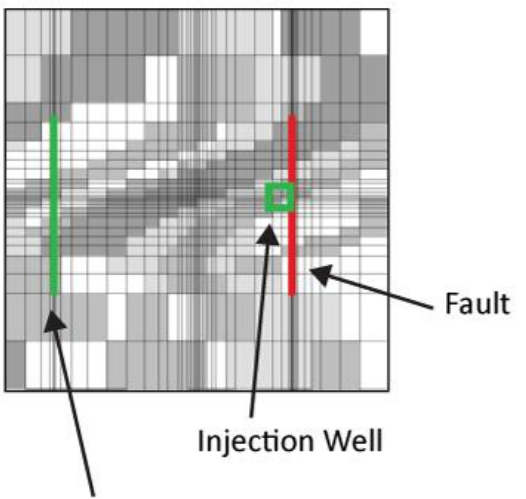

Horizontal Production Well

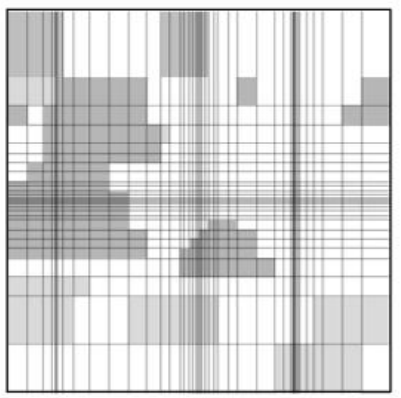

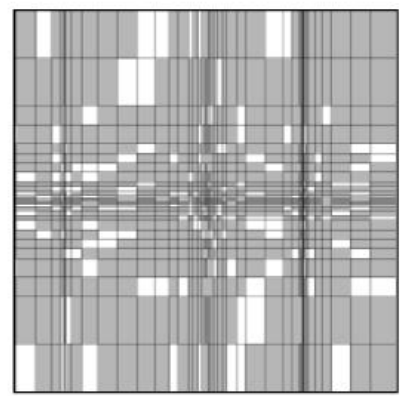

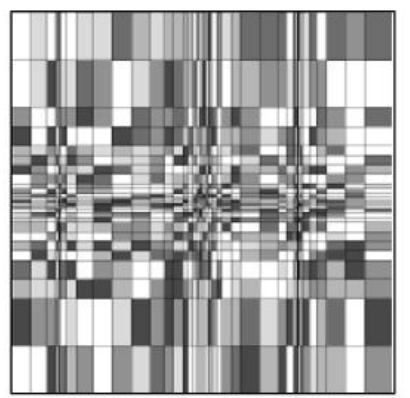

Fig 3. Top views of heterogeneous models for each of the lithofacies modeled. Clockwise from the top left are channels, layers, small dunes, and large dunes. Different shades of grey indicate different rock types. Only the $2 \mathrm{~km}$ x $2 \mathrm{~km}$ model centers where plume exists are shown.

\section{Base case leakage scenario}

As $\mathrm{CO}_{2}$ is injected at a constant rate of $7.9 \mathrm{~kg} / \mathrm{s}$ into the reservoir, brine is displaced away from the well and some brine begins to leak up the fault. Figure 4 shows the brine flow rate and associated pressure buildup in the overlying aquifer. After a period when only brine leaks up the fault, the $\mathrm{CO}_{2}$ injection plume eventually reaches the base of the fault; in this case, after 3.4 years. The pressure drops briefly when $\mathrm{CO}_{2}$ begins to migrate up the fault (also shown in Fig. 4) because the presence of $\mathrm{CO}_{2}$ lowers the relative permeability to water causing the brine flow rate to decrease rapidly. As the $\mathrm{CO}_{2}$ plume continues to advance in the lower reservoir, $\mathrm{CO}_{2}$ leakage increases as a result of: 1 ) the increasing relative permeability to $\mathrm{CO}_{2}, 2$ ) the length of fault exposed to the plume increases as the $\mathrm{CO}_{2}$ plume covers the entire base of the fault zone, and 3) the thickness of the $\mathrm{CO}_{2}$ plume underneath the fault grows, increasing the buoyancy force driving $\mathrm{CO}_{2}$ up the fault zone. After about 10 years the $\mathrm{CO}_{2}$ leakage rate stabilizes.

The exact timing and rates of potential $\mathrm{CO}_{2}$ leakage will vary depending on the geology of the injection reservoir, caprock, fault, and overlying aquifer as well as the geometry of the system (i.e. well and fault location). Previous work has shown that the reservoir and aquifer permeability are as important as the fault permeability in determining leakage rates (Zahasky and Benson 2014b). For example, when the overlying aquifer has a very low permeability relative to the injection reservoir, the reservoir injection pressure may be too low to overcome the capillary entry pressure of a low permeability overlying aquifer. Alternatively, if the overlying aquifer permeability is high relative to the reservoir permeability then the leakage rate is only limited by the fault permeability. If the fault permeability is also high relative to the injection reservoir permeability, the leakage rates are likely to be larger than those shown in Figure 4. While the timing and rates of leakage can vary significantly, the key 
stages of leakage are: (1) brine leakage, (2) $\mathrm{CO}_{2}$ leakage increasing at a declining rate and (3) approximately steady-state leakage. These three stages are observed in all of the cases examined here.

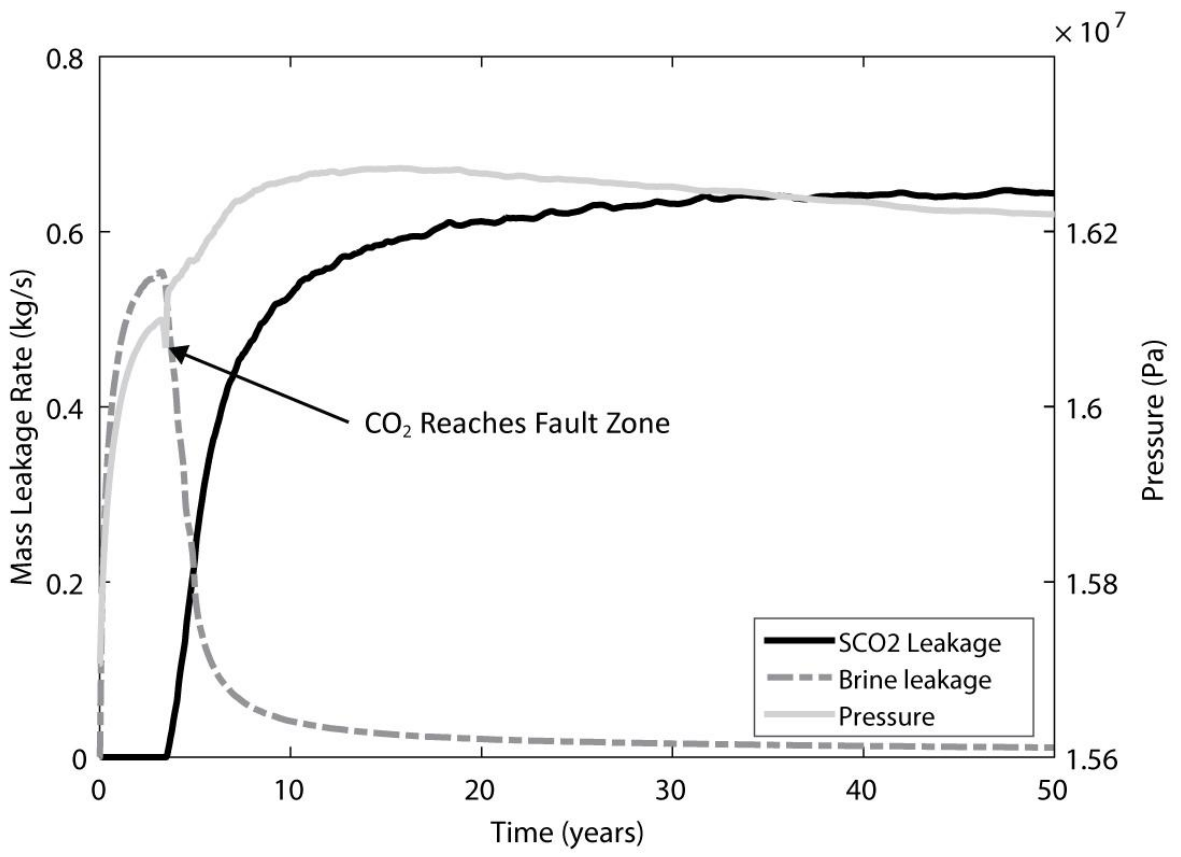

Time (years)

Fig 4. Brine leakage rate (dashed grey line) and $\mathrm{CO}_{2}$ leakage rate (black line) through the fault zone. The light grey line indicates the pressure (right axis) at the top of the fault as a function of time.

\section{6}

\section{Leakage intervention}

In this section a number of leakage intervention techniques will be explored. The first action that can be taken is to shutoff $\mathrm{CO}_{2}$ injection into the storage reservoir. Following this, additional measures such as hydraulic controls and $\mathrm{CO}_{2}$ production are explored. Hydraulic controls consist of water injection in the vicinity of the leakage plume and producing brine from the injection reservoir. Individually or in combination, these actions can stop the migration of $\mathrm{CO}_{2}$ up the fault zone, increase dissolution of $\mathrm{CO}_{2}$, displace $\mathrm{CO}_{2}$ away from the fault zone at the base of the caprock, and manipulate the $\mathrm{CO}_{2}$ plume geometry throughout the injection reservoir. All of the strategies presented here have been examined through a lens of practicality and feasibility of implementation. Specifically, we limited remediation activities to less than a decade, avoided pressure buildup from fluid injection that would exceed the fracture pressure, and ruled out injection and production strategies that included more than two wells due to cost considerations.

In order to explore how remediation efficacy is dependent on the quantity and rates of $\mathrm{CO}_{2}$ leaking from a storage reservoir, two initial leakage conditions are used. In the first scenario intervention begins five years after the start of $\mathrm{CO}_{2}$ injection, approximately two years after $\mathrm{CO}_{2}$ first begins to leak into the overlying reservoir. In this case about 5000 tons of $\mathrm{CO}_{2}$ has leaked into the overly aquifer, or roughly $0.5 \%$ of all of the $\mathrm{CO}_{2}$ injected into the system. The leakage plume size in the overlying aquifer in this scenario is $100 \mathrm{~m}$ wide and $300 \mathrm{~m}$ long. In the second scenario intervention begins 10 years after the start of $\mathrm{CO}_{2}$ injection. In this case the total amount of $\mathrm{CO}_{2}$ leaked is 76,000 tons, or roughly $3 \%$ of the total $\mathrm{CO}_{2}$ injected. The leakage plume in the overlying aquifer above is $500 \mathrm{~m}$ wide and $800 \mathrm{~m}$ long. Pressure monitoring (Hovorka et al. 2011; Meckel and Hovorka 2010; Bao et al. 2013; Picard et al. 2011; Birkholzer, Zhou and Tsang 2009; Chabora 2009) and seismic monitoring (Arts et al. 2004; Chadwick et al. 2005; Daley et al. 2008) are two commonly cited monitoring techniques shown to be capable of detecting plumes within this size range. 


\subsection{Injection shutoff}

Carbon dioxide injection shutoff prevents further pressure build up in the storage reservoir and over time allows the pore pressure in the reservoir to dissipate, lowering $\mathrm{CO}_{2}$ leakage rates. Figure 5 illustrates the impact that injection shutoff for each of the detection scenarios has on cumulative $\mathrm{CO}_{2}$ leakage compared with the scenario of continued $\mathrm{CO}_{2}$ injection. In the 5 year detection scenario, injection shutoff reduces the cumulative $\mathrm{CO}_{2}$ leakage after 50 years by over $97 \%$ (relative to the amount that would leak without any intervention) and in the 10 year detection scenario the reduction in cumulative $\mathrm{CO}_{2}$ leakage is over $85 \%$. In both detection scenarios, the pressure at the injection well returns to nearly initial conditions approximately four years after injection shutoff.

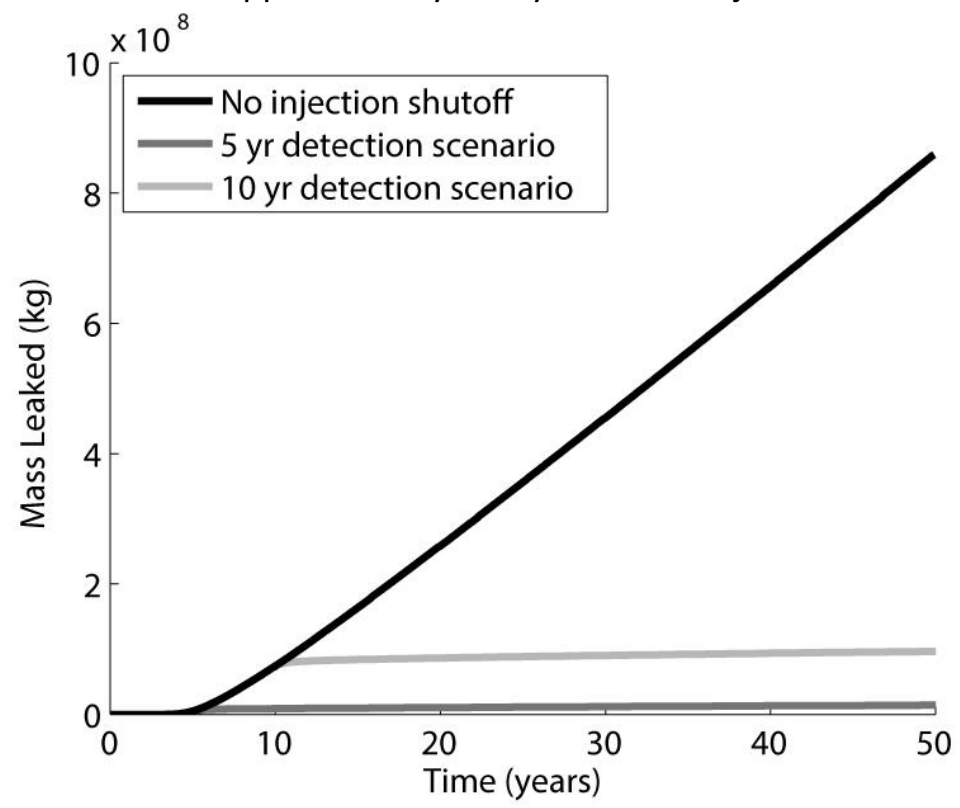

Fig 5. Comparison of injection shutoff at 5 years, shutoff at 10 years, and continued injection on the cumulative mass of $\mathrm{CO}_{2}$ leaked into the upper aquifer. The residual trapping coefficient for these simulations is set to $\mathrm{S}_{\mathrm{nmax}}=0.3$ and the fault permeability in this case is $10 \mathrm{mD}$ (from Zahasky and Benson 2014a).

To investigate the influence of trapping coefficients, the efficacy of injection shutoff is evaluated for scenarios where $S_{\text {nmax }}$ ranges from 0.0 to 0.5 while all of the other parameters remain fixed. Figure 6 shows the effect that different trapping coefficients have on the amount of leakage through a $10 \mathrm{mD}$ fault zone when injection is shutoff after 5 years. As residual trapping increases, the amount of mobile $\mathrm{CO}_{2}$ available to leak from the storage reservoir decreases, leading to lower leakage rates. As the Land residual trapping coefficient $\left(\mathrm{S}_{n \max }\right)$ approaches 0.5 , the leakage rate of $\mathrm{CO}_{2}$ from the storage reservoir following injection shutoff drops to nearly zero. As discussed in Section 2.3, coefficient values around 0.5 are possible under certain geologic conditions, however a coefficient value of $S_{n \max }=0.3$ appears to be typical for CCS storage reservoirs and is used in the remainder of this modeling study. 


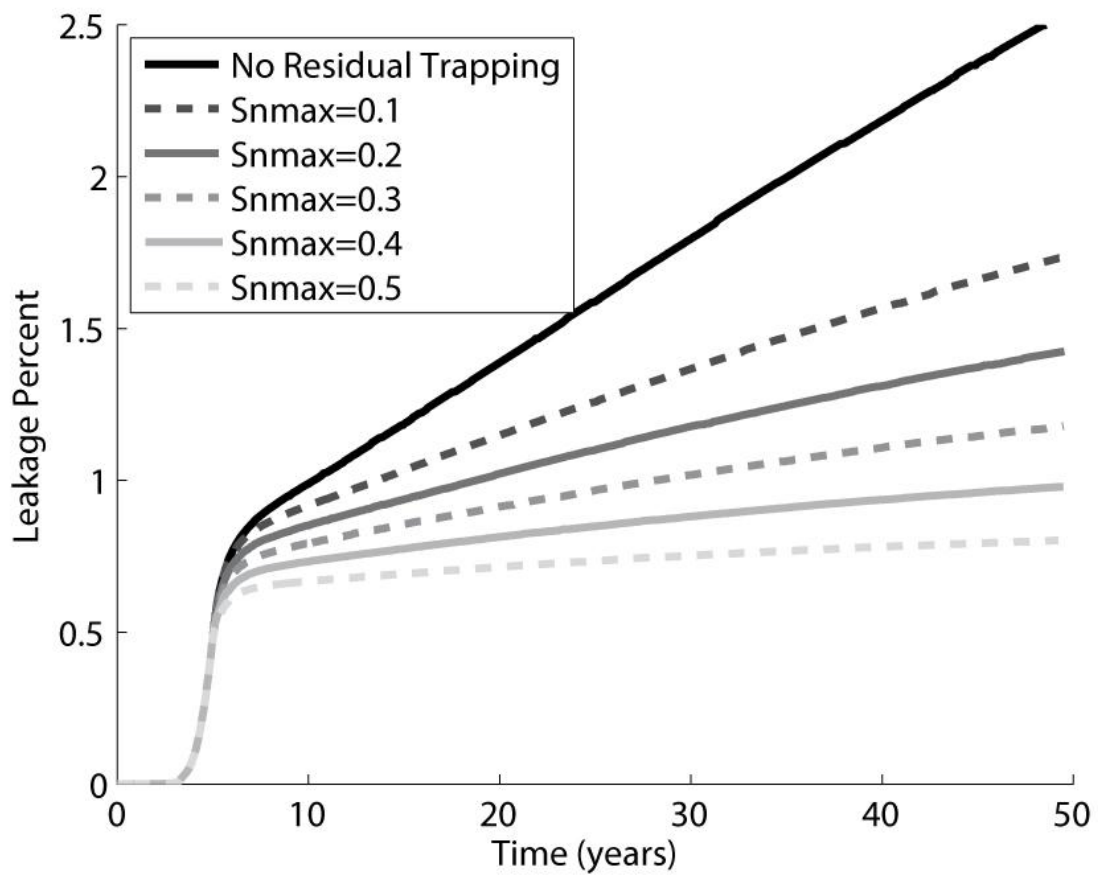

313 Fig 6. Influence of residual trapping on cumulative mass of $\mathrm{CO}_{2}$ leaked into the upper aquifer with injection shutoff occurring after 5 years in the homogenous model.

\subsection{Hydraulic Controls}

Following shutoff of injection it may be necessary to implement additional measures, in order to not just reduce leakage but, to terminate leakage completely. In this section a number of hydraulic control options are examined including water injection into the overlying aquifer, water injection at the base of the fault in the injection reservoir, and reservoir brine production. In all of the cases examined, intervention occurs after five years of $\mathrm{CO}_{2}$ injection and $\mathrm{CO}_{2}$ injection is terminated before implementing hydraulic controls. Two different fault permeability values are evaluated, $10 \mathrm{mD}$ (roughly one third of the reservoir permeability), and $100 \mathrm{mD}$ (approximately four times higher than the injection reservoir permeability). These two models provide insight into the sensitivity of fault permeability on both 324 leakage behavior and remediation effectiveness.

\section{5}

\subsubsection{Water Injection into the Overlying Aquifer}

Following $\mathrm{CO}_{2}$ injection shutoff there remains a buoyancy induced pressure gradient driving $\mathrm{CO}_{2}$ from the high-pressure injection reservoir into the lower pressure overlying aquifer. By injecting water into the overlying aquifer, pore pressure increases at the top of the fault, reducing and in some cases reversing the flow of $\mathrm{CO}_{2}$ in the fault zone. In addition to altering the pressure gradient in the reservoir water injection is able to dissolve a substantial fraction of the $\mathrm{CO}_{2}$ that has already leaked in the overlying aquifer. This dissolution trapping reduces the mobility of supercritical $\mathrm{CO}_{2}$ and permanently traps the $\mathrm{CO}_{2}$ dissolved in the water.

The geometry of the injection well will need to be determined by the length of the fault zone through which $\mathrm{CO}_{2}$ is leaking. Horizontal wells are able to more evenly distribute water and the resulting pressure buildup above the fault zone, whereas vertical wells concentrate the pressure build up at a single location in the overlying aquifer. All models in this study use a vertical injection well completed in only the top 5 meters of the overlying aquifer, only injection rates which kept the pressure build below roughly $150 \%$ of the initial pore pressure are considered. However, different storage sites will have to be 
evaluated individually in order to optimize water injection rates, considering among other factors, potential risks of hydraulic fracturing or induced seismicity.

For the given system it is important to understand how changing the water injection rate influences the rate of $\mathrm{CO}_{2}$ leakage from the storage reservoir. Figure 7 shows the results of a number of simulations in which the injection rates varied from $1 \mathrm{~kg} / \mathrm{s}$ to $3 \mathrm{~kg} / \mathrm{s}$. In all cases, water injection is able to completely terminate $\mathrm{CO}_{2}$ leakage during water injection, reduce the cumulative amount of $\mathrm{CO}_{2}$ that exists in overlying aquifer (Figure 7a), and completely immobilize nearly all of the $\mathrm{CO}_{2}$ in the overlying aquifer through dissolution trapping (Figure 7b). The reason for the significant drop in cumulative leakage is due to the dissolution of $\mathrm{CO}_{2}$-making the brine denser-and the continued water injection for 10 years which carries this dissolved $\mathrm{CO}_{2}$ back down the fault into the storage reservoir. It is important to note that increasing reservoir and aquifer salinity reduce the dissolution capacity of the system; for simplicity the salinity in these simulations is set to zero.

Results indicate that $\mathrm{CO}_{2}$ leakage in a homogeneous system can be quickly terminated by injection shutoff and water injection into the overlying aquifer. However in the cases examined here, $\mathrm{CO}_{2}$ leakage eventually resumes after the end of water injection due to the large volume of mobile $\mathrm{CO}_{2}$ present in the injection reservoir near the bottom of the fault zone. Therefore, injection of water in the aquifer is highly effective for quickly reducing leakage and may be used as a temporary containment method to stop leakage while the risks and benefits of additional remediation strategies are being evaluated.
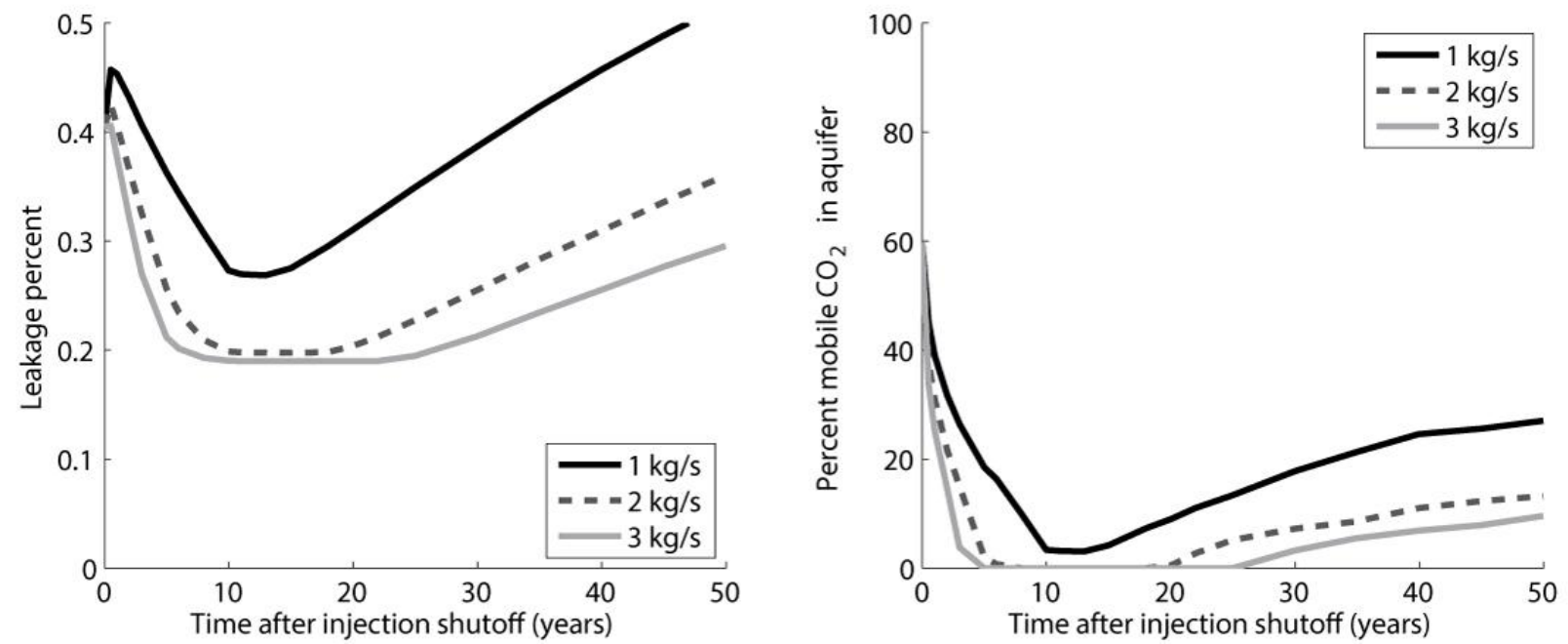

Fig 7. a. (left) Comparison of the influence of different injection rates on percent of $\mathrm{CO}_{2}$ in the upper aquifer. The leakage percent is calculated by dividing the total mass of $\mathrm{CO}_{2}$ in the aquifer by the total mass of $\mathrm{CO}_{2}$ injected into the system. In all cases, the injection rate is constant for the first 10 years, after which injection stops. b. (right) Percent of gas phase $\mathrm{CO}_{2}$ in the overlying aquifer.

\subsubsection{Reservoir Brine Production}

To suppress leakage for tens to hundreds of years after remedial actions end, further action can be taken to reduce the overall mobility of $\mathrm{CO}_{2}$ in the injection reservoir. With reservoir brine production it is possible to draw the $\mathrm{CO}_{2}$ plume away from the fault zone and further accelerate residual $\mathrm{CO}_{2}$ trapping.

Proper placement of the extraction well is essential for maximum $\mathrm{CO}_{2}$ mobility reduction. Early scoping studies found that the best location for a production well is on the far side of the injection plume from the fault zone (see description in Figure 3). Producing brine on the fault-side of the $\mathrm{CO}_{2}$ injection plume was found to increase the long-term $\mathrm{CO}_{2}$ leakage by pulling more $\mathrm{CO}_{2}$ into the region around the fault zone. In these simulations brine production takes place for 10 years from a well located $750 \mathrm{~m}$ away from the original $\mathrm{CO}_{2}$ injection well, far enough from the injection plume to avoid extracting $\mathrm{CO}_{2}$ from the storage reservoir. Figure 8 illustrates the reduction in leakage of $\mathrm{CO}_{2}$ using water injection activities combined with reservoir brine production through a horizontal well (dotted lines) compared with water injection without reservoir fluid production (solid lines). While brine production alone is 
insufficient to stop leakage into the overlying aquifer, when combined with water injection into the overlying aquifer it reduces cumulative $\mathrm{CO}_{2}$ leakage by roughly $25 \%$ after 100 years as compared to water injection alone.

In order to limit the costs of water storage and multiple water sources, all of the cases examined in this study have brine production rates equal to the total injection rate of $2 \mathrm{~kg} / \mathrm{s}$. This simultaneous injection and production addresses many of the financial and logistical concerns associated with largescale water injection activities. This assumption relies on the ability to inject reservoir water into the aquifer, which may not always be possible-or may require filtration or treatment-depending on the salinity, chemistry, and current and future utility of the reservoir and aquifer fluids.

\subsubsection{Water injection below the caprock}

The second possibility for reducing long-term $\mathrm{CO}_{2}$ mobility and leakage is to inject water below the fault in the injection reservoir. Water injection below the caprock is able to drive the $\mathrm{CO}_{2}$ plume away from the vicinity of the fault zone and dissolve any remaining $\mathrm{CO}_{2}$ in the area, the combination of which significantly increases the residual and dissolution trapping.

Initiation of water injection below the fault must take place sometime after the injection above the fault has stopped the $\mathrm{CO}_{2}$ leakage and re-saturated the fault with brine. Delayed water injection below the caprock prevents more $\mathrm{CO}_{2}$ from being pushed up the fault zone during this stage of remediation. In these simulations water is injected above the fault for two years before water injection below the fault zone begins at a rate of $2 \mathrm{~kg} / \mathrm{s}$ (light grey lines in Figure 8). When injection of water below the caprock begins, reservoir fluid production increases to $4 \mathrm{~kg} / \mathrm{s}$ in order to maintain an equal balance of water injected versus fluid produced. The water injection well in the storage reservoir is located directly below the water injection well in the overlying aquifer. This placement enables both injection activities to be performed using only one well perforated at two different intervals, one below the caprock and one above the caprock. In all of the simulations injection and production activities end after 10 years.

Results from this work indicate that the combination of all three hydraulic controls, water injection above and below the caprock and reservoir fluid production terminates leakage in the homogeneous model for decades. Figure 8 shows that when only injection shutoff is implemented, the leakage rates after 100 years drops to roughly 30 tons/year, or $0.003 \mathrm{~kg} /$ year, resulting in a cumulative leakage of 12,213 tons of $\mathrm{CO}_{2}$ in 100 years. For the $100 \mathrm{mD}$ fault, the highest leakage rates are roughly 300 tons per year after 100 years with a cumulative leakage percent of roughly $8 \%$ of the total $\mathrm{CO}_{2}$ injected into the system after 100 years. In both cases, the cumulative leakage values after 100 years drop in half when water injection occurs in the overlying aquifer. The rates drop nearly in half again with water injection both above and below the caprock. 

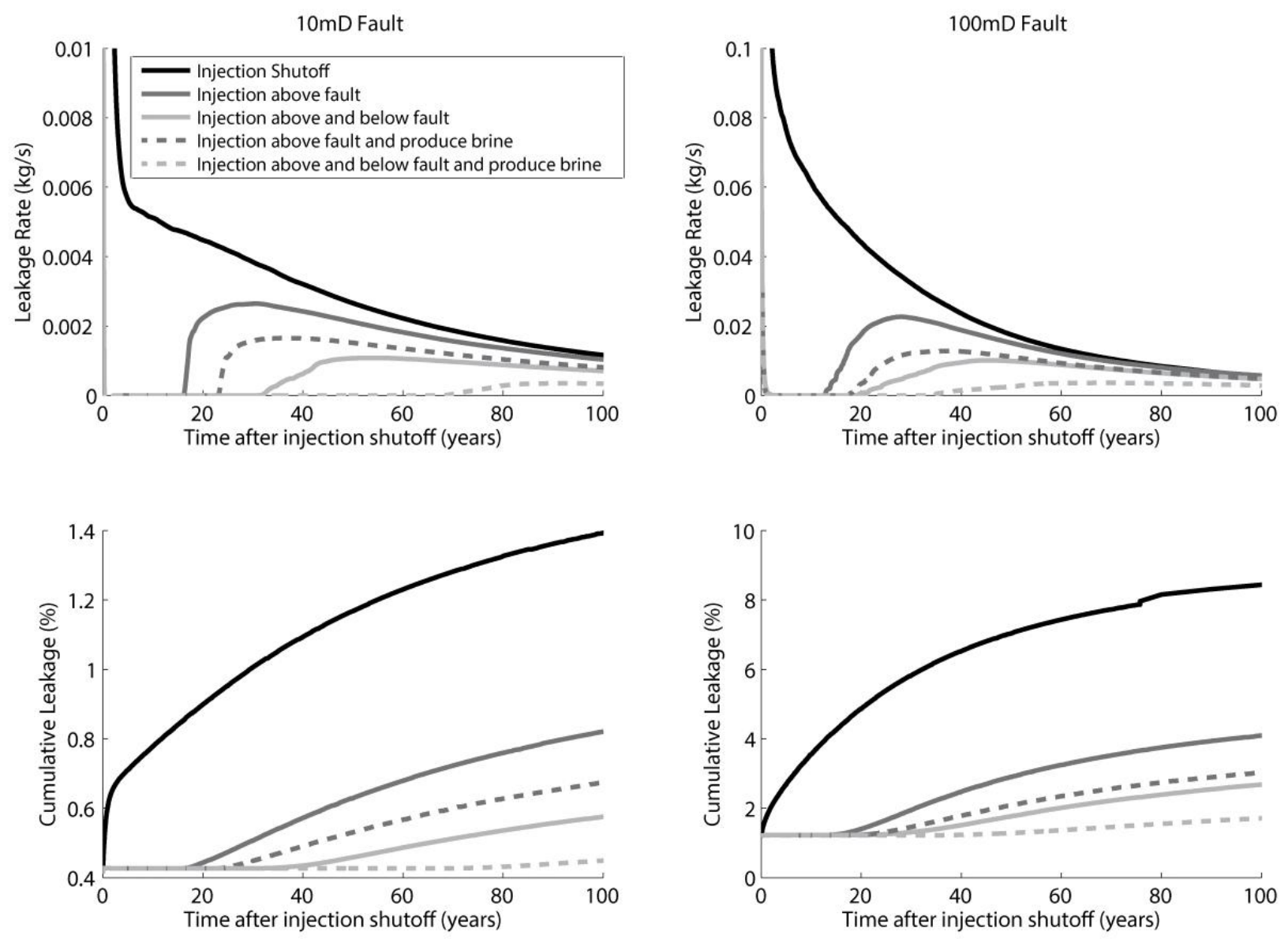

Fig 8. Comparison of different stages of remediation for a $10 \mathrm{mD}$ fault zone (left figures) and a $100 \mathrm{mD}$ fault zone (right figures), showing both leakage rates (top figures) and cumulative leakage percent as a function of time (bottom figures). Note the $y$-axis limits on the leakage rate figures are an order of magnitude larger in the $100 \mathrm{mD}$ fault scenario. The medium grey solid line corresponds to water injection of $2 \mathrm{~kg} / \mathrm{s}$ above the fault only, the dashed medium grey line corresponds to water injection and reservoir fluid production of $2 \mathrm{~kg} / \mathrm{s}$. The light grey line corresponds to water injection above the fault and below the fault at a rate of $2 \mathrm{~kg} / \mathrm{s}$ in each well. The dashed light grey line shows the leakage of $\mathrm{CO}_{2}$ in the case of injection of water below the fault, above the fault, and fluid production from the reservoir.

\subsection{Carbon dioxide production}

Carbon dioxide production from the original injection well can also be used as a means for remediation of $\mathrm{CO}_{2}$ leakage from the injection reservoir. Producing $\mathrm{CO}_{2}$ removes mobile $\mathrm{CO}_{2}$ in the injection reservoir and pulls brine into the periphery of the $\mathrm{CO}_{2}$ plume, increasing the amount of $\mathrm{CO}_{2}$ dissolved in brine and accelerating residual trapping. Simulations are run in which fluid production is performed through the original $\mathrm{CO}_{2}$ injection well for 10 years at constant mass production rates. Figure 9 shows both the fraction of total $\mathrm{CO}_{2}$ produced and fraction of produced fluid that is water (i.e. watercut) for several different fluid production mass flow rates. Due to the residual trapping and dissolution that take place in the system, even the highest production rates produce less than $40 \%$ of the injected $\mathrm{CO}_{2}$. At larger production rates the watercut increases; for the highest production rates almost $70 \%$ of the produced fluid is water. At production rates less than $2 \mathrm{~kg} / \mathrm{s}$, the fraction of produced water is less than $10 \%$ for over 5 years of production.

The effectiveness of carbon dioxide production for stopping $\mathrm{CO}_{2}$ leakage can also be compared with 430 the hydraulic control intervention methods (Figure 10). Results indicate that $\mathrm{CO}_{2}$ production at a 
431

relatively modest rate of $2 \mathrm{~kg} / \mathrm{s}$ is more effective in the short and long-term at reducing $\mathrm{CO}_{2}$ leakage from the storage reservoir than hydraulic control methods. Almost immediately after production starts, the leakage rate drops to zero. Based on these results, it is clear that $\mathrm{CO}_{2}$ production has a number of tradeoffs. It is very effective at stopping long-term leakage, however at least a quarter of the injected $\mathrm{CO}_{2}$ may have to be removed from the reservoir before leakage is stopped completely. This $\mathrm{CO}_{2}$ would need to be stored at another location. Otherwise, the benefits of CCS would be negated. Depending on the rate of production and other reservoir attributes, specifically heterogeneity, significant amounts of water would be produced and require disposal.
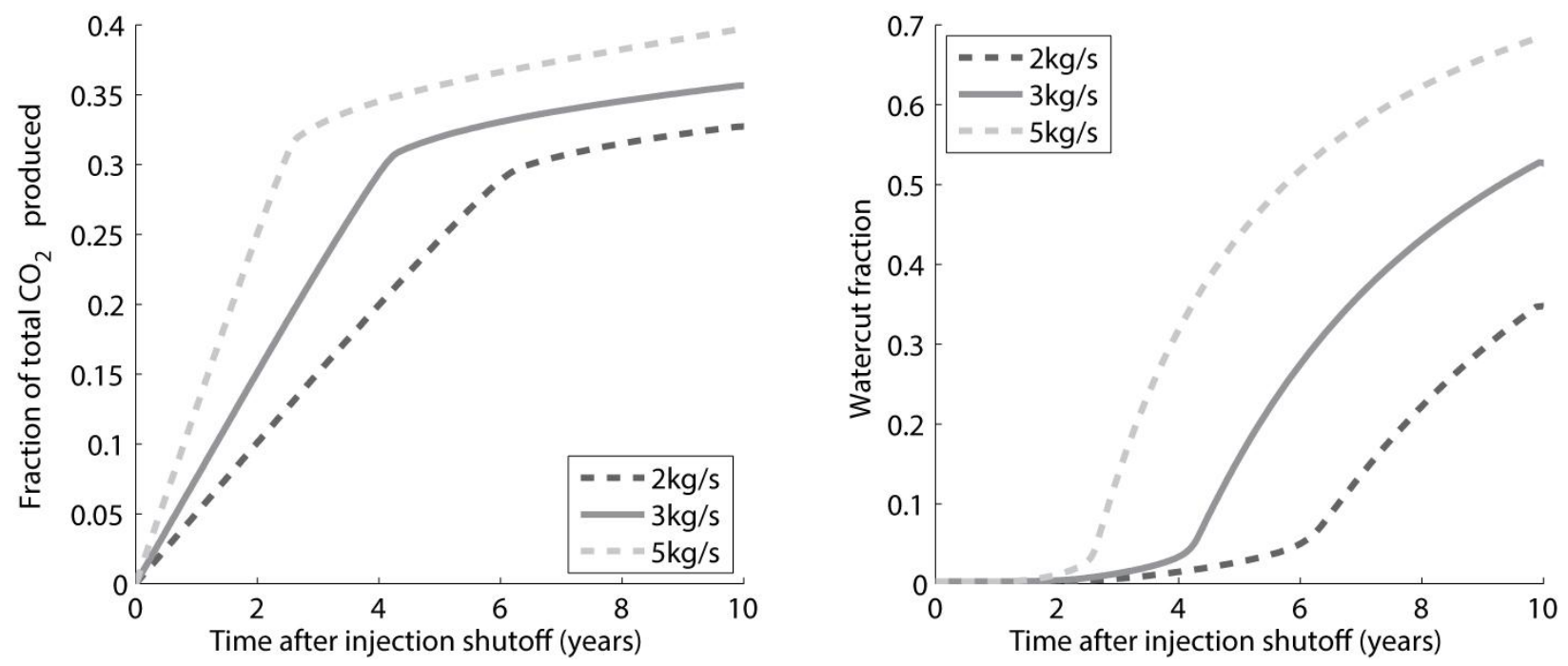

Fig 9 a. (left) Comparison of different production rates on the total percent of $\mathrm{CO}_{2}$ produced from the system. $\mathbf{b}$. (right) Comparison of watercut, or fraction of produced fluid that is water, for different fluid production rates.

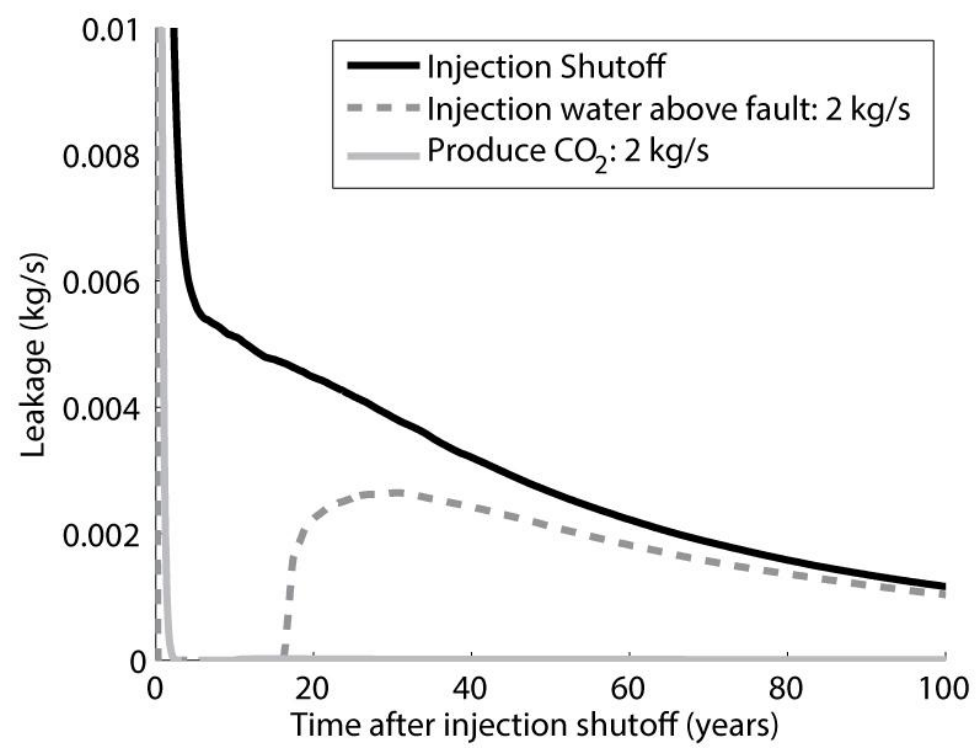

Fig 10. Comparison of injection shutoff, water injection, and $\mathrm{CO}_{2}$ production on the reduction of leakage through the fault zone in the model with a $10 \mathrm{mD}$ fault zone. 


\section{Leakage intervention in heterogeneous reservoirs}

In reality, since all reservoirs are heterogeneous it is essential to assess the degree to which the conclusions based on the investigation of homogeneous reservoirs can be extended to reservoirs with more realistic permeability distributions. Heterogeneity has the potential to create zones of high permeability that could allow more $\mathrm{CO}_{2}$ to reach the fault. However, heterogeneity can also create flow barriers and reservoir compartmentalization, slowing or potentially blocking $\mathrm{CO}_{2}$ from reaching the fault zone. The second question is to examine how leakage rates of both heterogeneous and homogenous systems respond to remediation on the century time scale rather than decadal time scale. The previous section focused on examining the impacts of various intervention methods on the short-term behavior of leakage from the reservoir. In this section, longer-term leakage rates will be examined in order to enable general risk assessment of future leakage from sequestration reservoirs. Finally, using the 5 year and 10 year detection scenarios outlined in the beginning of Section 4, what is the influence of early leakage detection on hydraulic barrier remediation effectiveness for both heterogeneous and homogenous systems?

The models used and developed in this section are identical to the homogeneous model with the exception of changes to grid cell permeability, porosity and capillary pressure characteristics as described in the heterogeneous model development section. All of the water injection and production activities are identical to the cases explored in the homogeneous models (i.e. water injection rates are 2 $\mathrm{kg} / \mathrm{s}$ for 10 years, fluid production rates match water injection rates). This enables direct comparison between homogenous model results and results from the heterogeneous models.

\subsection{Five year detection scenario}

Following the construction of the different heterogeneous models, the long-term leakage rates and percent of $\mathrm{CO}_{2}$ leaked into the aquifer could be calculated at the various stages of passive remediation and hydraulic barrier implementation. Results from the 5-year detection scenario are given in Figure 11. The red line in each graph corresponds to the values of the homogeneous base case model (long-term simulations results from models used in Figure 8 for the $10 \mathrm{mD}$ fault case). With passive remediation alone, the highest leakage percent is roughly $1.75 \%$ of the total $\mathrm{CO}_{2}$ injected 500 years after $\mathrm{CO}_{2}$ injection ends. The median leakage percent is under $1 \%$ (solid blue line). Both of these values drop in half when water injection-at $2 \mathrm{~kg} / \mathrm{s}$ for 10 years-is implemented. As in the homogeneous case, water injection prevents a significant amount of the leakage that occurs immediately after injection shutoff as the reservoir pressure is dissipating. After water injection stops, leakage resumes in about $75 \%$ of the heterogeneous models. Water injection at $2 \mathrm{~kg} / \mathrm{s}$ with a corresponding reservoir fluid production of 2 $\mathrm{kg} / \mathrm{s}$ further reduces the long-term leakage value to less than $1 \%$ of the total $\mathrm{CO}_{2}$ injected into the system in all models.

In the case where water is injected above the fault at $2 \mathrm{~kg} / \mathrm{s}$ for 10 years, injected below the fault at $2 \mathrm{~kg} / \mathrm{s}$, and reservoir brine is produced at $4 \mathrm{~kg} / \mathrm{s}$, the maximum leakage percent of any of the heterogeneous model is less than $0.3 \%$. For the homogeneous model, the leakage percent is over double the highest value of any of the heterogeneous models, around $0.7 \%$. Full implementation of all of the hydraulic controls leads to permanent leakage termination in over half of the heterogeneous models. In the models that experience some leakage following implementation of multistage hydraulic controls, the leakage rates are very small and most of the $\mathrm{CO}_{2}$ that exists in the overlying aquifer is a result of $\mathrm{CO}_{2}$ that leaked prior to intervention taking place.

In every model except one, the leakage percent in the models with heterogeneity are lower than leakage percent in the homogeneous model following injection shutoff. Following water injection above the caprock, reservoir fluid production, and/or injection below the caprock, the homogeneous model had the highest leakage percent. From these results, it can be concluded that heterogeneity often reduces the rates of $\mathrm{CO}_{2}$ leakage, and nearly always makes hydraulic controls more effective. In heterogeneous systems hydraulic controls are more effective because they are capable of dissolving and displacing mobile $\mathrm{CO}_{2}$ from the most permeable areas of the storage reservoir, while $\mathrm{CO}_{2}$ in low permeable regions of the reservoir remain effectively trapped by capillary forces following the termination of remediation. 

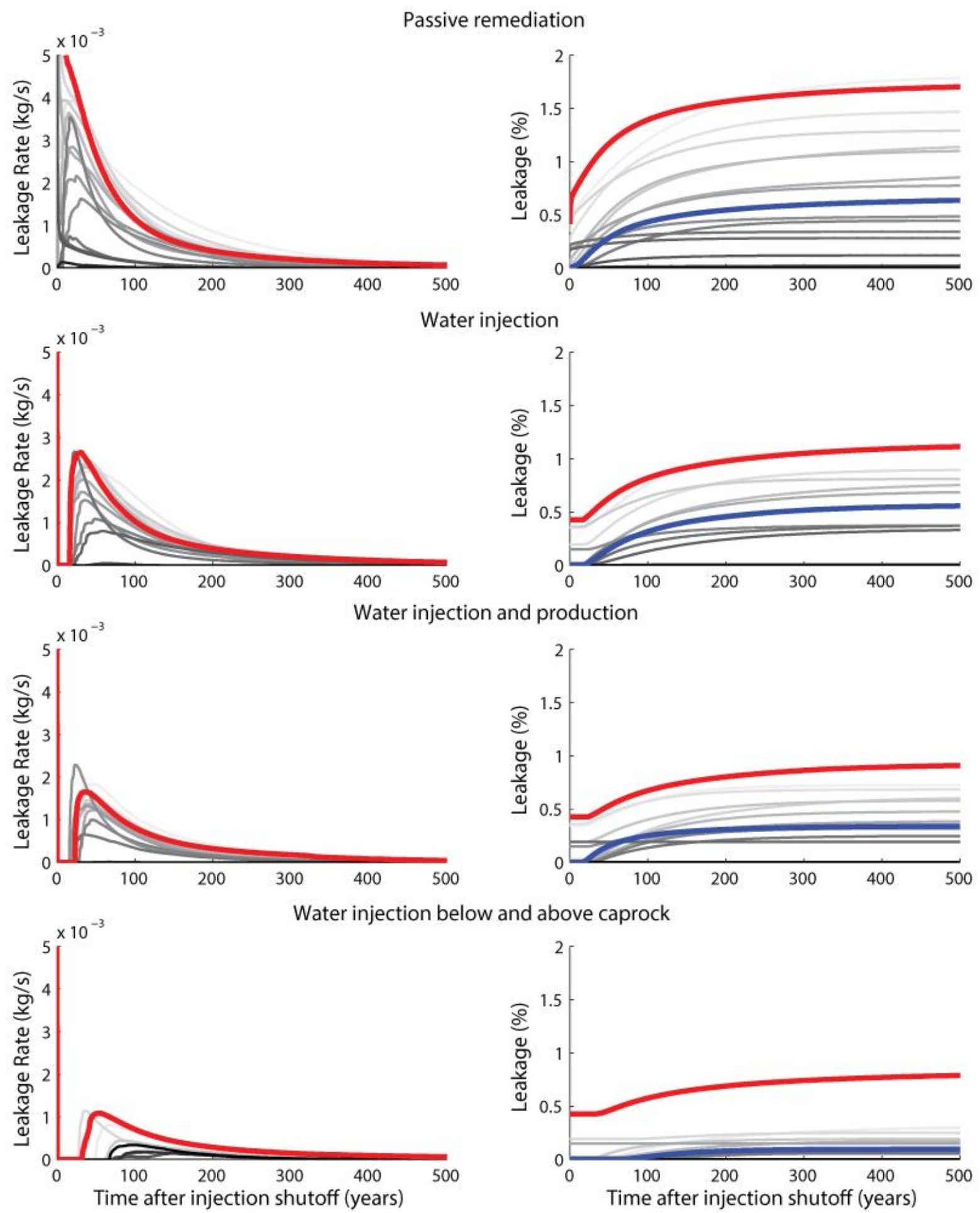

Fig 11. Homogeneous (dashed red line) and heterogeneous model responses (grey areas) to different stages of remediation when the leak is detected after 5 years of $\mathrm{CO}_{2}$ injection. The left column of plots show the mass leakage rate, the right column of plots show the cumulative leakage percent. The blue line indicates the median leakage model. 


\subsection{Ten year detection scenario}

In the 10-year detection scenario, over 10 times the amount of $\mathrm{CO}_{2}$ leaked into the overly aquifer relative to the 5-year detection scenario by the time intervention begins. In this leakage scenario, the initial leakage rates are roughly double the rates of the 5 -year detection scenario. Figure 12 shows the leakage rates and cumulative leakage percent for the different intervention options implemented after 10 years of leakage. With passive remediation alone, the highest leakage percent is roughly $3 \%$ of the total $\mathrm{CO}_{2}$ injected in the heterogeneous models, while it is almost $5 \%$ after 500 years in the homogeneous model. However, the median leakage percent is still roughly $1 \%$, similar to the 5 -year detection scenario. When water injection, at $2 \mathrm{~kg} / \mathrm{s}$ for 10 years, is implemented the maximum leakage after 500 years in the homogeneous model drops to $4 \%$ and the heterogeneous model drops to roughly $3 \%$.

The leakage rate response to water injection below and above the caprock highlights the importance of understanding the reservoir response to remediation techniques. In this scenario, one of the layered system models actually experiences a higher leakage rate as a result of water injection below the fault. While this model experienced a long-term leakage percent similar to other heterogeneous models, the leakage could have been lower if the remediation strategy had been customized for this particular geologic scenario.

Additional hydraulic controls such as water injection at $2 \mathrm{~kg} / \mathrm{s}$ with a corresponding reservoir fluid production of $2 \mathrm{~kg} / \mathrm{s}$ does very little to reduce the long-term leakage values in the models with the highest leakage rates. Similarly, in the case where water is injected above the fault at $2 \mathrm{~kg} / \mathrm{s}$ for 10 years, injected below the fault at $2 \mathrm{~kg} / \mathrm{s}$ and reservoir brine is produced at $4 \mathrm{~kg} / \mathrm{s}$, the maximum leakage percent in many of the heterogeneous models is again fairly close to the values of water injection alone. However, in almost half of the heterogeneous models leakage is permanently stopped with these additional hydraulic controls.

Comparing the results of these two detection scenarios provides a better understanding of the influence of leakage detection timing on the long-term leakage behavior. In the 5-year detection scenario, the majority of the $\mathrm{CO}_{2}$ that had leaked into the aquifer after 500 years came after the termination of remediation. However in the 10-year detection scenario, the majority of the $\mathrm{CO}_{2}$ that leaked into the overlying aquifer occurred prior to any intervention taking place. As a result, much more $\mathrm{CO}_{2}$ leaked into the overlying aquifer in the late detection scenario, reducing the efficacy hydraulic barrier options. This emphasizes both the importance of monitoring and early detection, as detecting the leak after 5 years of $\mathrm{CO}_{2}$ injection results in roughly a quarter of the leakage as compared to the 10year detection scenario. 
Passive remediation
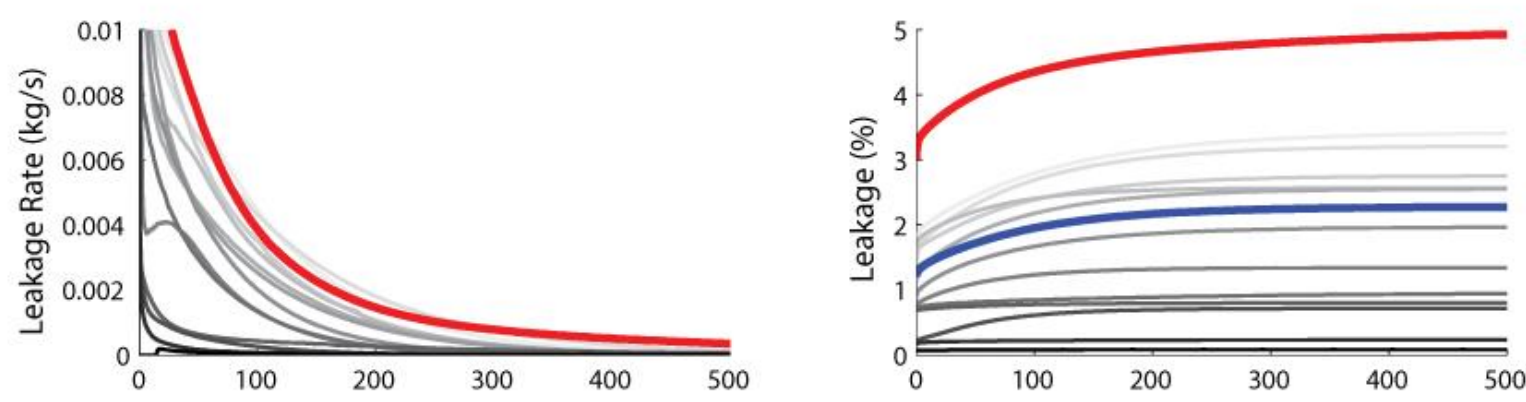

Water injection
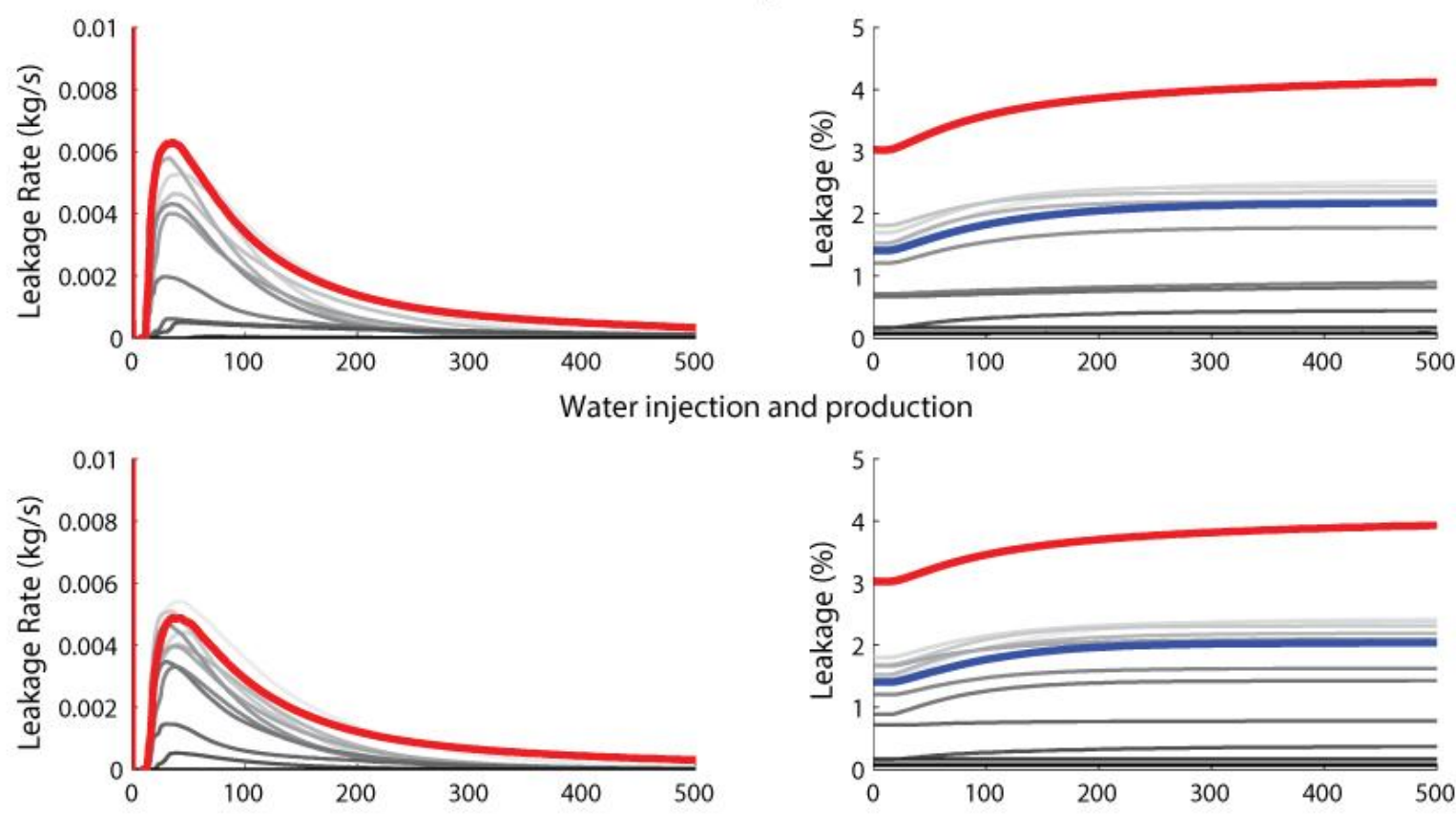

Water injection below and above caprock
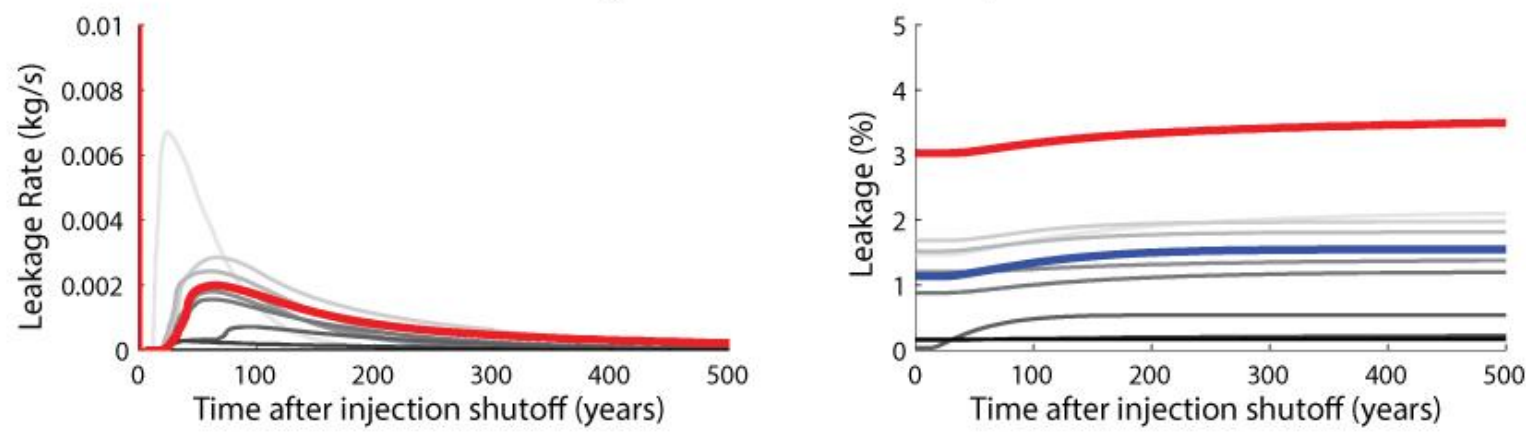

Fig 12. Homogeneous (red line) and heterogeneous model responses (grey areas) to different stages of remediation when the leak is detected after 10 years of $\mathrm{CO}_{2}$ injection. The left column of plots show the mass leakage rate, the right column of plots show the cumulative leakage percent. The blue line indicates the median leakage model. 


\section{Discussion}

Implementation of hydraulic controls in homogeneous systems was able to terminate $\mathrm{CO}_{2}$ leakage into an overlying aquifer by counteracting the fluid potential and buoyancy forces, and immobilizing much of the $\mathrm{CO}_{2}$ in the system. In the models used in this study, the fluid potential differences between the reservoir and overlying aquifer resulting from $\mathrm{CO}_{2}$ injection create a larger driving force than the buoyancy instability between the $\mathrm{CO}_{2}$ and resident reservoir fluid. As a result, stopping injection drops the leakage rate to a small fraction (less than 1/20th) of the initial leakage rate. While some leakage still occurs, it was very small and decreasing exponentially as the injected $\mathrm{CO}_{2}$ plume stabilizes due to secondary trapping mechanisms. This exponential decline in leakage rates cause the cumulative amount of $\mathrm{CO}_{2}$ leakage to stabilize after several centuries. For example, for a $10 \mathrm{mD}$ fault with $\mathrm{CO}_{2}$ injection shutoff after 5 years, the cumulative leakage was less than $2 \%$ of the total $\mathrm{CO}_{2}$ injected after 500 years (Figure 11). Stopping injection was only effective in completely stopping $\mathrm{CO}_{2}$ leakage if the buoyancy force acting on the $\mathrm{CO}_{2}$ plume below the fault falls below the capillary entry pressure of the fault zone. Additional studies are needed to better understand the capillary entry pressure of faults and fractures in caprock materials

Water injection was a very effective remediation technique because it increases the fluid potential in the overlying aquifer relative to the injection reservoir. This enables water injection to quickly stop leakage and in some cases push some amount of $\mathrm{CO}_{2}$ back down the fault. Water injection also dissolves large quantities of $\mathrm{CO}_{2}$, with the rates of dissolution dependent on the water injection rate and salinity of the injected water. However, leakage often resumes after water injection was terminated as the fluid potential in the aquifer drops below the fluid potential at the bottom of the fault.

Additional hydraulic controls such as reservoir fluid production and water injection below the caprock can be used to manipulate the fluid potentials in the system in the short term and increase rates $\mathrm{CO}_{2}$ trapping in the long term. In most cases, the addition of hydraulic controls can reduce the cumulative leakage after 500 years to less than $1 \%$ of the injected $\mathrm{CO}_{2}$ when early leakage detection occurs. In the homogeneous model for example, the combination of water injection above and below the fault with $\mathrm{CO}_{2}$ injection shutoff drops the cumulative amount of leakage to less than $0.8 \%$, and less than 0.0025 $\% /$ year was leaking after 500 years. If no intervention occurred then after only 40 years the total amount of $\mathrm{CO}_{2}$ leaked into the aquifer would be around 655,110 tons. When the leak was detected after 5 years of $\mathrm{CO}_{2}$ injection, and these intervention methods were implemented, the total mass of $\mathrm{CO}_{2}$ in the aquifer after 500 years was 14,000 tons and much of this $\mathrm{CO}_{2}$ was dissolved in water.

Carbon dioxide production from the storage reservoir has been shown to be very effective in stopping long-term $\mathrm{CO}_{2}$ leakage. The consequences of $\mathrm{CO}_{2}$ production vary depending on the extent of the $\mathrm{CO}_{2}$ injection operation. If multiple $\mathrm{CO}_{2}$ injection wells existed and the produced $\mathrm{CO}_{2}$ could be diverted to another injection well, the main challenge in implementing this method would be minimizing the water production and locating a new $\mathrm{CO}_{2}$ storage location. If other injection wells don't exist then the $\mathrm{CO}_{2}$ would likely have to be vented to the atmosphere thus negating all of the benefits that motivate the implementation of CCS.

Results from this study produced several findings that are important to the implementation and logistics of intervention with hydraulic controls. First, delivery of injected water can be through vertical or horizontal wells. The well geometry should be determined by the areal extent over which $\mathrm{CO}_{2}$ is leaking (e.g. fault zone length) and the limit on pore pressure build up in the overlying aquifer. Horizontal wells will be able to distribute the pressure buildup more evenly above the fault zone compared to a vertical water injection well. Second, one of the biggest benefits of water injection relative to other intervention options such as sealant delivery is that water injection doesn't require high precision leakage location because pressure build up due to injection will extend over hundreds of meters from the well location, depending on injection rates and aquifer properties. In all of the cases in this study, water injection through a vertical well located about ten meters from the center of the fault was able to completely stop $\mathrm{CO}_{2}$ leakage, even though the fault length is $500 \mathrm{~m}$. The vertical well successfully stopped leakage at the tips of the fault zone roughly 250 meters from the location of the well. Finally, water injection in the overlying aquifer and injection reservoir can occur in the same well perforated at different intervals, as done in this study. If brine production from the reservoir is 
implemented, an additional well will have to be drilled because fluid production around the fault zone pulls more $\mathrm{CO}_{2}$ in to the region.

Understanding the extent to which different trapping mechanisms contribute to leakage reduction and plume stabilization for different forms of remediation is vital for optimizing intervention effectiveness and understanding the time duration required for remediation. Figure 13 shows the extent of different mechanisms of trapping for different intervention scenarios 10 years (left figures) and 100 years (right figures) after $\mathrm{CO}_{2}$ injection ends. Figure 13 also shows differences between trapping in the entire system (top row) and trapping in the overlying aquifer (bottom row). Several important insights can be gained from this analysis. First, producing $20 \%-30 \%$ of the total $\mathrm{CO}_{2}$ reduces the mobile $\mathrm{CO}_{2}$ in the entire system more than with any other intervention technique. Second, immediately following water injection in the overlying aquifer, all of the $\mathrm{CO}_{2}$ in the aquifer was dissolved; this leads to significantly higher rates of solubility trapping in the long term. Finally, the amount of residually trapped and dissolved $\mathrm{CO}_{2}$ increases with time, leading to less mobile $\mathrm{CO}_{2}$ in the system and thus decaying leakage rates. The exact amount of trapping as a function of time will control how long hydraulic controls are necessary. This trapping behavior is in good agreement with other studies (e.g. Doughty and Myer 2009) and emphasizes the fact that the highest risks of $\mathrm{CO}_{2}$ leakage will be during the injection phase of $\mathrm{CO}_{2}$ storage and that risk of leakage from the storage reservoir will decrease with time after $\mathrm{CO}_{2}$ injection in the reservoir is terminated.

One of the most notable results of this work was the influence of reservoir heterogeneity on $\mathrm{CO}_{2}$ and on remediation efficacy. The models used in this study indicate that much more $\mathrm{CO}_{2}$ leakage occurs in the homogeneous model relative to the heterogeneous models prior to the initiation of remediation. Flow barriers and reservoir compartmentalization caused by heterogeneity in the injection reservoir leads to lower $\mathrm{CO}_{2}$ leakage rates and often leads to a longer delay between beginning $\mathrm{CO}_{2}$ injection in the storage reservoir and the initiation of $\mathrm{CO}_{2}$ leakage up the fault. Additionally, cumulative leakage for the heterogeneous scenarios was almost half of the cumulative leakage for the homogeneous case in nearly every model and in every intervention scenario. We did not focus on upper aquifer heterogeneity because the pressure buildup for hydraulic control will eventually extend over the overlying aquifer, regardless of the permeability distribution. The pressure buildup will occur first on the highest permeability zones and later in the lower permeability zones. The magnitude of the pressure buildup will be controlled primarily by the injection rate and the average permeability-thickness of the overlying aquifer. Furthermore, in previous work we have found that when upper aquifer permeability is two or more orders of magnitude below the reservoir permeability, there is very little leakage and hence remediation will not be required (Zahasky and Benson 2013b). Alternatively, if the upper aquifer permeability is much higher than the storage reservoir then the injectivity should be favorable for hydraulic barrier implementation.

Early leakage detection is vital for effective remediation with hydraulic barriers because remediation is more effective when less $\mathrm{CO}_{2}$ has leaked and the column of $\mathrm{CO}_{2}$ beneath the fault is thinner. This is supported by results from the heterogeneous models in the 10-year detection scenario. The models with the highest leakage rates show very little response to brine production and water injection below the caprock relative to results when leakage was detected after 5 years. Additionally, in the 5-year detection scenario, the majority of the $\mathrm{CO}_{2}$ that had leaked into the aquifer came after the termination of remediation. However, in the 10-year detection scenario, the majority of the $\mathrm{CO}_{2}$ that leaked into the overlying aquifer took place prior to initiation of intervention. Nevertheless, the hydraulic controls were very effective at reducing further leakage once they were implemented. 
10 years after intervention begins

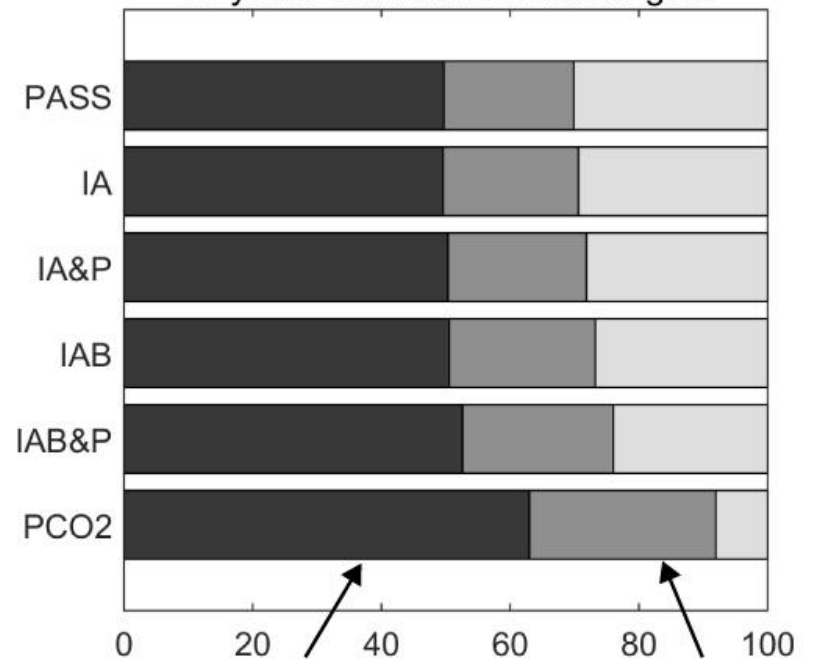

Residual trapping

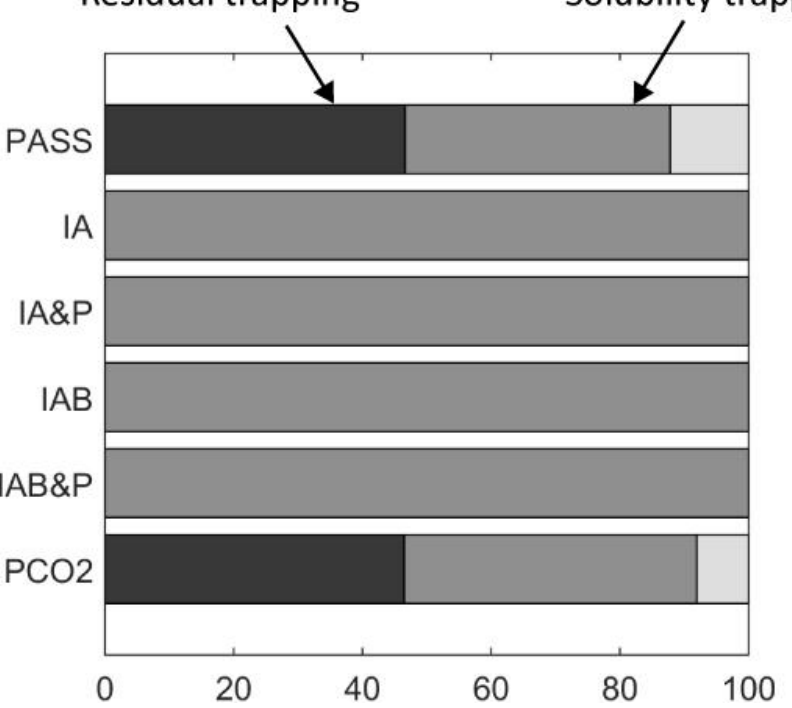

100 years after intervention begins

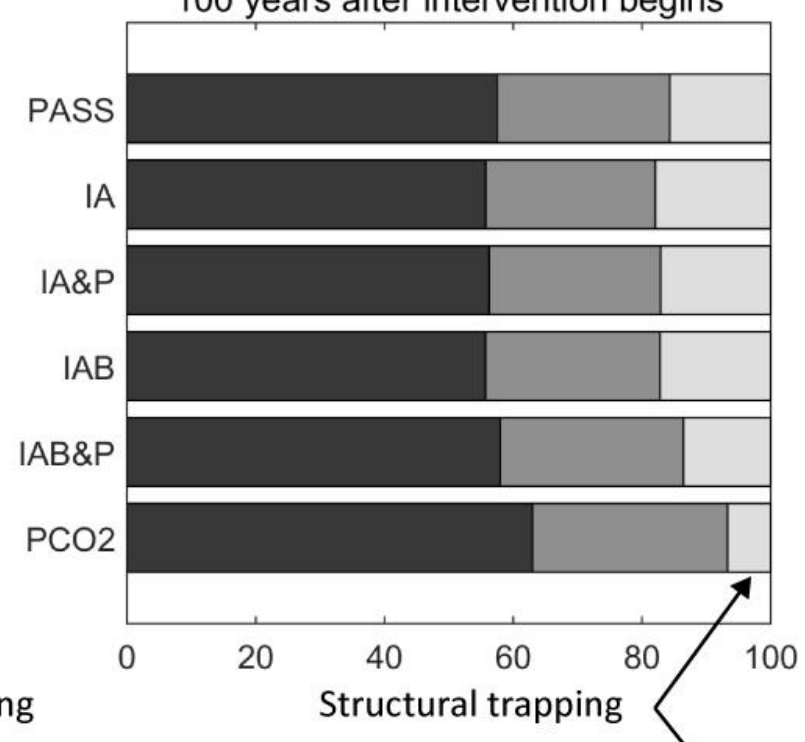

636

Fig 13. (top row) Extent of different $\mathrm{CO}_{2}$ trapping mechanisms (residual, solubility, or structural) in the entire system for different remediation options 10 years and 100 years after $\mathrm{CO}_{2}$ injection is terminated. (bottom row) Contribution of different trapping mechanisms of $\mathrm{CO}_{2}$ in the overlying aquifer for different remediation options. The abbreviations for the different remediation options are: PASS = passive remediation/ injection shutoff, IA = injection in overlying aquifer and no fluid production, IA\&P = injection in overlying aquifer and balanced reservoir fluid production, $I A B=$ injection above and below the caprock without production of reservoir fluid, $I A B \& P=$ injection above and below the caprock with equal production of reservoir fluid, $\mathrm{PCO} 2=$ production of $\mathrm{CO}_{2}$.

\section{Conclusion}

Hydraulic controls provide a valuable technique for remediation of $\mathrm{CO}_{2}$ leakage from storage reservoirs when the geographic location of the leakage point is uncertain or if the leakage is occurring over a large spatial region as would be expected for leakage up faults, fractures, or high permeability zones in the caprock. In this study, three different leakage intervention strategies were evaluated: $\mathrm{CO}_{2}$ injection shutoff, hydraulic controls (specifically water injection and reservoir fluid production), and $\mathrm{CO}_{2}$ production from the reservoir. The goal of implementing these techniques is to depressurize the injection reservoir, counteract the buoyant flow of $\mathrm{CO}_{2}$ from the storage reservoir to the upper aquifer, 
and enhance residual and dissolution trapping of mobile $\mathrm{CO}_{2}$. A range of models were built in order show how residual trapping, fault permeability, timing of leakage detection, and heterogeneity influenced the efficacy of the different intervention strategies.

Prior to analyzing more sophisticated and costly remediation strategies, the impact of $\mathrm{CO}_{2}$ injection shutoff was first analyzed. In the event of leakage up a fault, detection and shutoff will reduce the mass that would otherwise have leaked from the storage reservoir by over $85 \%$ percent. In some cases, particularly if the leak is detected early, shutting off injection will be all that is required to manage the risks caused by leakage. However, in most cases, shutting off injection is not sufficient to completely stop the leak.

In this case, additional hydraulic controls such as water injection and brine production provide an effective means to remediate leakage of $\mathrm{CO}_{2}$ from storage reservoirs. Water injection above and below the fault is able to push $\mathrm{CO}_{2}$ down, and away from, the fault zone while enhancing dissolution trapping. Results of this study indicate that even relatively small injection rates are able to terminate $\mathrm{CO}_{2}$ leakage during water injection. Leakage may resume following the termination of water injection, though leakage may be delayed by a decade or more. This highlights the importance of evaluating the efficacy of remediation on the multi-decade to century timescale.

Producing reservoir fluid away from the fault zone is shown to further increase the efficacy of remediation. Fluid production decreases the pressure in the reservoir, enhances dissolution and residual $\mathrm{CO}_{2}$ trapping by roughly $5 \%-10 \%$, and provides water for injection activities. Removing $\mathrm{CO}_{2}$ by extracting it from the original $\mathrm{CO}_{2}$ injection well is a very effective means of remediation in the short and long term, however there are significant drawbacks to removing injected $\mathrm{CO}_{2}$. The extracted $\mathrm{CO}_{2}$ would need to be transported and stored in a new location to avoid releasing it back into the atmosphere.

To our knowledge this is the first paper to analyze the influence of reservoir heterogeneity on $\mathrm{CO}_{2}$ leakage behavior and remediation. This study illustrates that reservoir heterogeneity generally decreases leakage rates and makes remediation and mitigation efforts more effective. Heterogeneity introduces flow barriers that restrict $\mathrm{CO}_{2}$ migration and structurally trap injected $\mathrm{CO}_{2}$. Furthermore, injected water is able to penetrate higher permeability regions of the reservoir near the fault zone enabling the displacement of $\mathrm{CO}_{2}$ to regions of the storage reservoir away from the fault zone. This indicates that in heterogeneous formations multistage hydraulic controls may not always be necessary. Future intervention planning and modeling should include site-specific reservoir heterogeneity as this will have important implications for the intensity of remediation necessary to completely terminate leakage.

Regardless of initial leakage rates, this study emphasizes that the highest leakage rates are always during, or immediately following the end of $\mathrm{CO}_{2}$ injection. Long-term leakage rates declined in an exponential fashion in all cases examined in this study as the $\mathrm{CO}_{2}$ plume in the injection reservoir and overlying aquifer stabilized due to continuous and ongoing $\mathrm{CO}_{2}$ trapping. Regardless of fault permeability, detection timing, and heterogeneity, it is possible to terminate leakage with injection shutoff and multistage hydraulic barriers. The findings from this study should provide assurances to industry, policy makers, and the public that intervention measures can quickly and effectively mitigate potential leakage from carbon sequestration reservoirs and that long-term risks of leakage are smaller than during the operational phases of $\mathrm{CO}_{2}$ injection activities.

\section{Acknowledgements}

This project was supported by the Stanford University Department of Energy Resources Engineering and the Stanford Center for Carbon Storage. This work is part of a larger project, "Assessment of Leakage Detection and Intervention Scenarios for $\mathrm{CO}_{2}$ Sequestration," supported by the CCP3; a joint industry project sponsored by BP, Chevron, Eni, Petrobras, Shell, and Suncor.

\section{Nomenclature}

$$
\mathrm{S}_{\mathrm{i}} \quad=\text { initial gas saturation }
$$




\section{Appendix}

705 Table A1: Summary of model properties

\begin{tabular}{|l|l|}
\hline Reservoir Attributes & Value \\
\hline Upper aquifer permeability (mD) & 28 \\
\hline Aquifer porosity (\%) & 10 \\
\hline Aquifer thickness & 20 \\
\hline Lower reservoir permeability (mD) & 28 \\
\hline Reservoir porosity (\%) & 10 \\
\hline Reservoir thickness & 68 \\
\hline Buoyancy: angle of caprock (deg) & 0 \\
\hline Caprock permeability (nD) & 0.2 \\
\hline Caprock porosity (\%) & 5 \\
\hline Caprock Thickness & 12 \\
\hline Salinity (mass fraction of NaCl) & 0 \\
\hline Capillary pressure $\lambda$ (van Genuchten) & 0.295 \\
\hline Reservoir capillary pressure $1 / \mathrm{P}_{0}(\mathrm{van}$ & $2.83 \times 10^{-5}$ \\
Genuchten) & \\
\hline Residual brine trapping & 0.2 \\
\hline Rock Density (kg/m ${ }^{3}$ ) & 2600 \\
\hline Initial pressure (Pa) & $\sim 1.6 \times 10^{7}$ \\
\hline Temperature - isothermal ( $\left.{ }^{\circ} \mathrm{C}\right)$ & 48 \\
\hline Fault Zone Attributes & $10 / 100$ \\
\hline Permeability (mD) & 10 \\
\hline Porosity (\%) & 500 \\
\hline Fault Zone Length (m) & 3 \\
\hline Fault Zone Thickness (m) & 500 \\
\hline Distance from injection well (m) & \\
\hline
\end{tabular}

707 Table A2: Summary of lithotope properties

\begin{tabular}{|l|l|l|l|}
\hline Lithotope & Permeability $(\mathbf{m D})$ & Porosity $(\%)$ & van Genuchten $\mathbf{P}_{\mathbf{0}}(\mathbf{k P a})$ \\
\hline Coarse sand & 1000 & 25 & 9.344 \\
\hline Medium sand & 100 & 15 & 22.89 \\
\hline Med-fine sand & 28 & 10 & 35.30 \\
\hline
\end{tabular}




\begin{tabular}{|l|l|l|l|}
\hline Find sand & 10 & 10 & 59.10 \\
\hline Very fine sand & 1 & 10 & 186.9 \\
\hline Shale & 0.01 & 8 & 1,671 \\
\hline
\end{tabular}

708

709

710

711

712

713 


\section{References}

715

716

717

718

719

720

721

722

723

724

725

726

727

728

729

730

731

732

733

734

735

736

737

738

739

740

741

742

743

744

745

746

747

748

749

750

751

752

753

754

755

756

757

758

759

Akbarabadi, M., Piri, M., 2013. Relative permeability hysteresis and capillary trapping characteristics of supercritical $\mathrm{CO}_{2}$ /brine systems: An experimental study at reservoir conditions. Advances in Water Resources, 52, 190-206.

Antonellini, M., Aydin, A., 1994. Effect of Faulting on Fluid Flow in Porous Sandstones: Petrophysical Properties. AAPG Bulletin, 78, 355-377.

Arts, R., Eiken, O., Chadwick, A., et al., 2004. Monitoring of $\mathrm{CO}_{2}$ injected at Sleipner using time-lapse seismic data. Energy, 29, 1383-1392.

Bachu, S., 2013. Drainage and imbibition of $\mathrm{CO}_{2}$ /brine relative permeability curves at in situ conditions for sandstone formations in western Canada. Proceedings of the $11^{\text {th }}$ International Conference on Greenhouse Gas Control Technologies, Energy Procedia, 37, 4428-4436.

Bao, B., Melo, L., Davies, B., et al., 2013. Detecting supercritical $\mathrm{CO}_{2}$ in brine at sequestration pressure with an optical fiber sensor. Environmental science \& technology, 47, 306-13.

Bennion, B., Bachu, S., 2005. Relative Permeability Characteristics for Supercritical $\mathrm{CO}_{2}$ Displacing Water in a Variety of Potential Sequestration Zones in the Western Canada Sedimentary Basin. SPE 95547

Bennion, B., Bachu, S., 2008. Drainage and imbibition relative permeability relationships for supercritical $\mathrm{CO}_{2}$ /brine and $\mathrm{H}_{2} \mathrm{~S} /$ brine systems in intergranular sandstone, carbonate, shale, and anhydrite rocks. SPE Reservoir Evaluation and Engineering, 11, 487-496.

Benson, S.B., Cook, P., 2005. Underground geological storage. IPCC $5^{\text {th }}$ Assessment Report Chapter 5.

Birkholzer, J., Zhou, Q., Tsang, C., 2009. Large-scale impact of $\mathrm{CO}_{2}$ storage in deep saline aquifers: A sensitivity study on pressure response in stratified systems. International Journal of Greenhouse Gas Control, 3, 181-194.

Burnside, N.M., Naylor, M., 2014. Review and implications of relative permeability of $\mathrm{CO}_{2} /$ brine systems and residual trapping of $\mathrm{CO}_{2}$. International Journal of Greenhouse Gas Control, 23, 1-11.

Buscheck, T.A., Sun, Y., Chen, M., et al., 2012. Active $\mathrm{CO}_{2}$ reservoir management for carbon storage: Analysis of operational strategies to relieve pressure buildup and improve injectivity. International Journal of Greenhouse Gas Control, 6, 230-245.

Caine, J.S., Evans, J.P., Forster, C.B., 1996. Fault zone architecture and permeability structure. Geology, 24, 1025-1028.

Celia, M.A., Bachu, S., Nordbotten, J.M., Gasda, S.E., Dahle, H.K., 2005. Quantitative Estimation of $\mathrm{CO}_{2}$ Leakage from Geological Storage: Analytical Models, Numerical Models, and Data Needs. Greenhouse Gas Control Technologies, 1, 663-671.

Chabora, E.R., 2009. The utility of above-zone pressure measurements in monitoring geologically stored carbon dioxide. Master's Thesis.

Chadwick, R.A., Arts, R., Eiken, O., 2005. 4D seismic quantification of growing $\mathrm{CO}_{2}$ plume at Sleipner, North Sea. Petroleum Geology: North-West Europe and Global Perspectives-Proceedings of the $6^{\text {th }}$ Petroleum Geology Conference, 1385-1399.

Cowie, P.A., Scholz, C.H., 1992. Displacement-length scaling relationship for faults: data synthesis and discussion. Journal of Structural Geology, 14, 1149-1156.

Cunningham, A.B., Gerlach, R., Spangler, L., Mitchell, A.C., 2009. Microbially enhanced geologic containment of sequestered supercritical $\mathrm{CO}_{2}$. Energy Procedia, 1, 3245-3252.

Daley, T.M., Myer, L.R., Peterson, J.E., Majer, E.L., Hoversten, G.M., 2008. Time-lapse crosswell seismic and VSP monitoring of injected $\mathrm{CO}_{2}$ in a brine aquifer. Environmental Geology, 54, 1657-1665.

Dockrill, B., Shipton, Z.K., 2010. Structural controls on leakage from a natural $\mathrm{CO}_{2}$ geologic storage site: Central Utah, USA. Journal of Structural Geology, 32, 1768-1782. 
Doughty, C., Myer, L.R., 2009. Scoping Calculations on Leakage of $\mathrm{CO}_{2}$ in Geologic Storage: The Impact of Overburden Permeability, Phase Trapping, and Dissolution. Carbon Sequestration and Its Role in the Global Carbon Cycle (eds B. J. Mcpherson and E. T. Sundquist), American Geophysical Union, Washington, D. C.

Elliott, D., 1976. The Energy Balance and Deformation Mechanisms of Thrust Sheets. Philosophical Transactions of the Royal Society A: Mathematical, Physical and Engineering Sciences, 283 (1312), 289-312.

Esposito A., Benson S.M., 2012. Evaluation and development of options for remediation of $\mathrm{CO}_{2}$ leakage into groundwater aquifers from geologic carbon storage. International Journal of Greenhouse Gas Control, (7) 62-73.

Evans, J.P., 1990. Thickness-displacement relationships for fault zones. Journal of Structural Geology, 12(8), 1061-1065.

Fisher, Q.J., Knipe, R.J., 2001. The permeability of faults within siliciclastic petroleum reservoirs of the North Sea and Norwegian Continental Shelf. Marine and Petroleum Geology, 18, 1063-1081.

Fossen, H., Schultz, R.A., Shipton, Z.K., Mair, K., 2007. Deformation bands in sandstone: a review. Journal of the Geological Society, 164, 755-769.

Friedmann, S.J., Nummedal, D., 2003. Reassessing the Geological Risks of Seal Failure for Saline Aquifers and EOR Projects. EOR Projects: Second Annual Conference on Carbon Sequestration.

Gauthier, B., Lake, S., 1993. Probabilistic modeling of faults below the limit of seismic resolution in Pelican Field, North Sea, offshore United Kingdom. AAPG Bulletin, 77, 761-777.

Gunter, W.D., Bachu, S., Benson, S.M., 2004. The role of hydrogeological and geochemical trapping in sedimentary basins for secure geological storage of carbon dioxide. Geological Society, London, Special Publications, 223, 129-145.

Hovorka, S. et al., 2011. Monitoring a large volume CO2 injection: Year two results from SECARB project at Denbury's Cranfield, Mississippi, USA. Energy Procedia, 4, 3478-3485.

Hull, J., 1988. Thickness-displacement relationships for deformation zones. Journal of Structural Geology, 10 (4), 431-435.

Ito, T., Xu, T., Tanaka, H., Taniuchi, Y., Okamoto, A., 2014. Possibility to remedy $\mathrm{CO}_{2}$ leakage from geological reservoir using $\mathrm{CO}_{2}$ reactive grout. International Journal of Greenhouse Gas Control, 20, 310-323.

Kim, Y.S., Sanderson, D.J., 2005. The relationship between displacement and length of faults: a review. Earth-Science Reviews, 68, 317-334.

Knott, S.D., Beach, A., Brockbank, P.J. et al., 1996. Spatial and mechanical controls on normal fault populations. Journal of Structural Geology, 18, 359-372.

Krantz, R.W., 1988. Multiple fault sets and three-dimensional strain: Theory and application. Journal of Structural Geology, 10, 225-237.

Krevor, S.C.M., Pini, R., Zuo, L., Benson, S.M., 2012. Relative permeability and trapping of $\mathrm{CO}_{2}$ and water in sandstone rocks at reservoir conditions. Water Resources Research, 48, 1-16.

Krevor, S., Blunt, M. J., Benson, S. M., Pentland, C. H., Reynolds, C., Al-Menhali, A., Niu, B., 2015. Capillary trapping for geologic carbon dioxide storage-From pore scale physics to field scale implications. International Journal of Greenhouse Gas Control.

Laforce, T., Ennis-King, J., Boreham, C., Paterson, L., 2014. Residual $\mathrm{CO}_{2}$ saturation estimate using noble gas tracers in a single-well field test : The CO2CRC Otway project. International Journal of Greenhouse Gas Control, 26, 9-21.

Land, C., 1968. Calculation of Imbibition Relative Permeability for Two- and Three-Phase Flow from Rock Properties. Society of Petroleum Engineers Journal, 8(2). 
806

807

808

809

810

811

812

813

814

815

816

817

818

819

820

821

822

823

824

825

826

827

828

829

830

831

832

833

834

835

836

837

838

839

840

841

842

843

844

845

846

847

848

849

850

851

852

853

Le Guénan, T., Rohmer, J., 2011. Corrective measures based on pressure control strategies for $\mathrm{CO}_{2}$ geological storage in deep aquifers. International Journal of Greenhouse Gas Control, 5, 571578.

Manceau, J.-C., Hatzignatiou, D.G., de Lary, L., Jensen, N.B., Reveillere, A., 2014. Mitigation and remediation technologies and practices in case of undesired migration of $\mathrm{CO}_{2}$ from a geological storage unit-Current status. International Journal of Greenhouse Gas Control, 22, 272-290.

Matthai, S.K., Aydin, A., Pollard, D.D., Roberts, S.G., 1998. Simulation of transient well-test signatures for geologically realistic faults in sandstone reservoirs. SPE Journal 38442.

McPherson, B.J.O.L., Cole, B.S., 2000. Multiphase $\mathrm{CO}_{2}$ flow, transport and sequestration in the Powder River Basin, WY, USA. Journal of Geochemical Exploration. 69-70, 65-69.

Meckel, T., Hovorka, S., 2010. Above-Zone Pressure Monitoring as a Surveillance Tool for Carbon Sequestration Projects. Proceedings of SPE International Conference on CO2 Capture, Storage, and Utilization, 1-7.

Meckel, T.A., Zeidouni, M., Hovorka, S.D., Hosseini, S.A., 2013. Assessing sensitivity to well leakage from three years of continuous reservoir pressure monitoring during $\mathrm{CO}_{2}$ injection at Cranfield, $\mathrm{MS}$, US. International Journal of Greenhouse Gas Control, 18, 439-448.

Muraoka, H., Kamata, H., 1983. Displacement distribution along minor fault traces. Journal of Structural Geology, 5, 483-495.

Nordbotten, J.M., Celia, M.A., Bachu, S., 2004. Analytical solutions for leakage rates through abandoned wells. Water Resources Research, 40, W04204.

Opheim, J.A., Gudmundsson, A., 1989. Formation and geometry of fractures, and related volcanism, of the Krafla fissure swarm, northeast Iceland. Geological Society of America Bulletin, 101, 16081622.

Paterson, L., Boreham, C., Bunch, M. et al., 2013. Overview of the CO2CRC Otway residual saturation and dissolution test. Energy Procedia, 37, 6140-6148

Patterson, C.G., Falta, R.W., 2012. PROCEEDINGS, TOUGH Symposium 2012 Lawrence Berkeley National Laboratory, Berkeley, California, September 17-19, 2012.

Peacock, D., 1991. Displacements and segment linkage in strike-slip fault zones. Journal of Structural Geology, 13, 1025-1035.

Peacock, D., Sanderson, D., 1991. Displacements, segment linkage and relay ramps in normal fault zones. Journal of Structural Geology, 13, 721-733.

Pentland, C.H., El-Maghraby, R., Iglauer, S., Blunt, M.J., 2011. Measurements of the capillary trapping of super-critical carbon dioxide in Berea sandstone. Geophysical Research Letters, 38.

Perrin, J.C., Benson, S.M., 2010. An experimental study on the influence of sub-core scale heterogeneities on $\mathrm{CO}_{2}$ distribution in reservoir rocks. Transport in Porous Media, 82, 93-109.

Picard, G., Berard, T., Chabora, S., Marsteller, S., et al., 2011. Real-time monitoring of $\mathrm{CO}_{2}$ storage sites: Application to Illinois Basin-Decatur Project. Energy Procedia, 4, 5594-5598.

Pickering, G., Peacock, D., 1997. Modeling tip zones to predict the throw and length characteristics of faults. AAPG Bulletin, 81, 82-99.

Pini, R., Krevor, S.C.M., Benson, S.M., 2012. Capillary pressure and heterogeneity for the $\mathrm{CO}_{2} /$ water system in sandstone rocks at reservoir conditions. Advances in Water Resources, 38, 48-59.

Pruess, K., Oldenburg, C., Moridis, G. 1999. TOUGH2 user's guide, Version 2.0. Tech. Rep., Lawrence Berkeley National Laboratory, Earth Sciences Division, LBNL-43134

Pruess, K., 2005. ECO2M: A TOUGH2 Fluid Property Module for Mixtures of Water, $\mathrm{NaCl}$, and $\mathrm{CO}_{2}$, Including Super- and Sub-Critical Conditions, and Phase Change between Liquid and Gaseous $\mathrm{CO}_{2}$. User Manual

Remy, N., Boucher, A., Wu, J. 2009. Applied Geostatistics with SGeMS: A User's Guide. Cambridge University Press. 
854 Réveillère, A., Rohmer, J., Manceau, J.C., 2012. Hydraulic barrier design and applicability for managing the risk of $\mathrm{CO}_{2}$ leakage from deep saline aquifers. International Journal of Greenhouse Gas Control, 9, 62-71.

Ruprecht, C., Pini, R., Falta, R., Benson, S., Murdoch, L., 2014. Hysteretic trapping and relative permeability of $\mathrm{CO}_{2}$ in sandstone at reservoir conditions. International Journal of Greenhouse Gas Control, 27, 15-27.

Shi, J.Q., Xue, Z., Durucan, S., 2011. Supercritical $\mathrm{CO}_{2}$ core flooding and imbibition in Tako sandstoneinfluence of sub-core scale heterogeneity. International Journal of Greenhouse Gas Control, 5, 75-87.

Sperrevik, S., Gillespie, P.A., Fisher, Q.J., Halvorsen, T., Knipe, R.J., 2002. Empirical estimation of fault rock properties. Hydrocarbon Seal Quantification, 11, 109-125.

Walsh, J.J., Watterson, J., 1988. Analysis of the relationship between displacements and dimensions of faults. Journal of Structural Geology, 10, 239-247.

Zahasky, C., 2014. Quantification and Intervention Strategies for potential leakage from carbon storage reservoirs. Master's Thesis.

Zahasky, C., Benson, S.M., 2014a. Evaluation of the effectiveness of injection termination and hydraulic controls for leakage containment. International Conference for Greenhouse Gas Technology-12, Austin, Texas, October 6-9, 2014.

Zahasky, C., Benson, S.M., 2014b. A simple approximate semi-analytical solution for estimating leakage of carbon dioxide through faults. International Conference for Greenhouse Gas Technology-12, Austin, Texas, October 6-9, 2014. 